\title{
La filosofía de la ética profesional: una historia entrañable*
}

\author{
David Luban \\ Bradley Wendel
}

\begin{abstract}
RESUMEN
La teoría de la ética profesional, como disciplina moderna, comenzó en los 1970. Este artículo ofrece un breve recuento bistórico distinguiendo dos oleadas de literatura teórica respecto de ética de la profesión jurídica. La "Primera Oleada" vincula la disciplina con la filosofía moral, y se concentra en los conflictos que se producen entre la moral ordinaria de los abogados y su ética del rol, mientras que la "Segunda Oleada" se preocupa más bien del papel que juega la representación jurídica en la mantención y promoción de una democracia pluralista. El artículo rastrea el origen de la Primera Oleada en los movimientos sociales de los 1960 y 1970. En la conclusión, ofrecemos algunas especulaciones acerca de posibles caminos que podría tomar una Tercera Oleada de ética profesional teórica, sobre la base de la ética conductual, la ética de las virtudes, o la teoría de la relación fiduciaria.
\end{abstract}

Ética profesional - moral ordinaria - ética del rol - teoría del derecho

\section{Philosophical Legal Ethics: An Affectionate History}

\begin{abstract}
The modern subject of theoretical legal etbics began in the 1970s. This brief history distinguishes two waves of theoretical writing on legal ethics. The "First Wave" connects the subject to moral philosophy and focuses on conflicts between ordinary morality and lawyers' role morality, while the "Second Wave" focuses instead on the role legal representation plays in maintaining and fostering a pluralist democracy. We trace the emergence of the First Wave to the larger social movements of the 1960s and 1970s; in the conclusion, we speculate about possible directions for a Third Wave of theoretical legal ethics, based in behavioral ethics, virtue ethics, or fiduciary theory.
\end{abstract}

Legal ethics - ordinary morality - role morality - jurisprudence

* Traducción de Javier Gallego Saade. Este artículo apareció publicado originalmente en inglés, bajo el título "Philosophical Legal Ethics: An Affectionate History", en The Georgetown Journal of Legal Ethics, vol. 30, 2017, pp. 337-361.

Artículo recibido el 31.7.2019 y aceptado para su publicación el 6.3.2020. 


\section{INTRODUCCIÓN}

$\mathrm{E}$ 1 historiador inglés del partido Whig Thomas Babington Macauly, entrenado como abogado, cuestionó alguna vez, con aire de superioridad, la disposición que tenía el abogado, "que usa una peluca en su cabeza, y una cinta alrededor de su cuello, [a] hacer por una guinea lo que, sin esos apéndices, consideraría malvado e infame hacer por un imperio" ${ }^{1}$. Dejemos de lado la referencia a la guinea; la pregunta central es: ¿qué tipo de persona se siente, por el solo hecho de ocupar un rol social, libre para hacer a un lado deberes y virtudes humanas universales? De alguna forma, el problema de la "ética del rol" de abogado es uno de los problemas más antiguos de la filosofía: se remonta a la crítica de Platón a los sofistas ${ }^{2}$. A pesar de eso, sorprendentemente muy pocos juristas -y filósofos morales- se preocuparon de la ética profesional del abogado en los siglos previos a la década de 1970. Hubo abundante discusión en torno a algunos lugares comunes ${ }^{3}$, pero muy poco análisis teórico sostenido ${ }^{4}$. En los años '70, sin embargo, algo inesperado ocurrió. Comenzó una repentina efusión de artículos y monografías sobre teorías de ética profesional, que dieron origen a la disciplina moderna. Su origen y rápido crecimiento resulta fascinante como pieza de análisis histórico, lo que de paso nos aporta mucha información sobre la profesión misma y cómo esta ha evolucionado desde entonces.

La conmemoración de la Revista de Ética Profesional de Georgetown, en la que el presente artículo se inserta, es la ocasión apropiada para examinar esta historia. El Padre Robert Drinan, fundador de la Revista, acogía a los filósofos (uno de nosotros, Luban, recuerda una llamada telefónica del Padre Drinan, quien en su usual entusiasmo contagioso comenzó diciendo "Hola, soy Bob Drinan, ¿qué piensas de mi Revista?” Hasta

${ }^{1}$ David Luban, Lawyers and Justice: An Ethical Study (1988), p. xxi.

${ }^{2}$ Véase, por ejemplo, Platón, Gorgias, en The Collected Dialogues (Edith Hamilton \& Huntington Cairns, eds., 1961) (W.D. Woodhead, trad.). Por "ética del rol" queremos decir los deberes y mandatos morales asociados a un rol social - por ejemplo, los deberes morales de confidencialidad y celo del abogado, como también el mandato moral del abogado de promover los intereses del cliente incluso a expensas de otros intereses más valiosos.

${ }^{3}$ El ex juez de la Corte Suprema Federal Tom C. Clark presidió un comité especial para la ABA, que luego sería conocido como la "Comisión Clark", dedicada al estudio de disciplina de abogados. Ha sido identificada como el punto de partida de la revolución del campo de la ética profesional. Véase VINCENT R. Johnson, “Justice Tom C. Clark's Legacy in the Field of Legal Ethics”, 29 J. Legal Prof., pp. 33, 35 (2002). Sin embargo, las contribuciones más conocidas del Juez Clark a este ámbito, en su calidad individual, son notorias más bien por sus piadosas generalidades, como por ejemplo la afirmación de que la lección más importante del escándalo de Watergate es que la integridad moral e intelectual son importantes, y que la organización profesional ha pasado de ser una noble profesión a un negocio hambriento de ganancias. Véase Tom C. Clark, "Teaching Professional Ethics" 12 San Diego L. Rev., p. 249 (1975). Desafortunadamente, muchos de los comentarios en materia de ética profesional de esa época, en particular de parte de distinguidos líderes de organizaciones profesionales, o de jueces, tienen esa cualidad homilética.

${ }^{4}$ La única excepción fue Lon Fuller, un gran filósofo del derecho de la Universidad de Harvard; pero cuyos escritos sobre ética profesional de las décadas de 1950 y 1960 fueron en gran parte ignorados por los círculos académicos (en su mayor parte, todavía lo son). Véase David Luban, "Rediscovering Fuller's Legal Ethics”, 11 Geo. J. Legal Ethics 801 (1998), reimpreso en Rediscovering Fuller: Essays on Implicit Law and Institutional Design (Willem J. Witteveen \& Wibren van der Burg, eds., 1999). 
ese momento, solo nos habíamos encontrado una vez). La visión que Drinan tenía era de una revista que abordara problemas prácticos, no solo teóricos, pero entendía muy bien lo profundamente entrelazada que estaba la ética profesional con la teoría. Drinan entendía también que el renovado interés en problemas morales fundamentales conectado con la función del abogado le daría impulso a las velas de la producción académica en ética profesional, y eso hizo que la Revista de Ética Profesional de Georgetown se volviera no solo necesaria sino posible.

El breve recuento histórico que sigue es selectivo, y -quisiéramos enfatizar- muy personal, en lo que respecta a los autores. Otros participantes en la evolución del discurso de la teoría de ética profesional de seguro narrarían la historia de una manera diferente. No nos disculpamos por ofrecer una historia personalizada; sí le ofrecemos disculpas a los académicos que pasamos por alto. Dado los constreñimientos de espacio y el deseo de no ahondar demasiado en algunos de los debates, no reclamamos exhaustividad del recuento histórico que sigue. Hay varias contribuciones de importantes académicos que han quedado fuera de esta revisión. Además, la historia que contamos se remite en lo fundamental a Estados Unidos.

Por razones que no entendemos completamente, la ética profesional filosófica floreció en Estados Unidos más de una década antes que atrajera atención internacional.

En lo que sigue identificaremos dos "oleadas" de contribuciones académicas concernientes a teoría de ética profesional: una que mira la profesión a través de los lentes de la filosofía moral, y otra posterior que critica esta orientación filosófico-moral y se aproxima a la profesión más bien desde la filosofía política. Resumidamente, la primera oleada se concentra en el abogado individual en tanto agente moral, y analiza la tensión moral entre la vida ética, por un lado, y la ética del rol del abogado a la que se refería Macaulay. La segunda oleada, en cambio, tematiza la representación jurídica como una institución política situada en una democracia pluralista, y por esa vía conecta la ética profesional con la pregunta por los elementos necesarios para que le sea posible a esa profesión jurídica preservar instituciones pluralistas. Cronológicamente, la primera oleada comenzó en la década de los 70 y la segunda oleada en los 2000. Pero obviamente esta división es formal: por cierto, estas dos escuelas de pensamiento se superponen en el tiempo mucho más que lo que sugiere la metáfora de "dos oleadas".

En la conclusión, ofrecemos breves especulaciones acerca de temas discutidos actualmente en la literatura especializada que podrían abrir el paso hacia una tercera oleada de pensamiento respecto de ética profesional.

\section{LA PRIMERA OLEADA: LA ÉTICA PROFESIONAL COMO UN PROBLEMA DE FILOSOFÍA MORAL}

\section{A. El trasfondo social y politico}

La primera oleada de contribuciones y reflexiones académicas pertinente a ética profesional surgió a partir de la agitación social y política de las décadas de los 1960 y 
1970. Este era el tiempo de Martin Luther King, de Malcolm X, y de la lucha por la igualdad racial. También marcaba el inicio del movimiento feminista moderno. También, y muy importantemente, era el tiempo de la guerra de Vietnam y del movimiento pacifista. Para muchas personas, de mayor edad y jóvenes, pero principalmente para los jóvenes, la guerra puso en evidencia, de forma definitiva, la carencia moral del liberalismo americano de guerra fría, que mostraba un lento progreso en la igualdad en casa, pero justificaba agresivas intervenciones en el exterior. Esto llevó a una severa pérdida de confianza política en las instituciones. Este era también el tiempo de la contracultura. Notoriamente, esa contracultura se rebeló contra el conformismo y el arribismo, que veía como vaciados de contenido espiritual. Las instituciones cayeron en sospecha, incluyendo las instituciones jurídicas. La conciencia individual, según esta visión del mundo, debe siempre vencer a las presiones institucionales 5 .

La actitud de estos movimientos, tanto en lo político como en lo cultural, era antiautoritaria y marcadamente moralista. Mirando hacia atrás, podemos decir que, quizás, estos movimientos carecían de una visión política general. Como muchos movimientos sociales, sabían a qué se oponían, pero no tenían muy claro exactamente qué es lo que defendían. Por cierto, los movimientos se caracterizaban por ser extremadamente moralistas y arrogantes. Pero no hay duda de que, en esos tiempos de agitación, la postura de antiautoridad era considerada el piso mínimo que requería la decencia humana. La idea de que las personas debían obedecer a las autoridades parecía moralmente demencial cuando se las estaba obligando a ir a Vietnam a matar personas.

Las escuelas de derecho estadounidenses no fueron inmunes a estas corrientes sociales. La nueva izquierda en la academia legal ya estaba activa a mediados de los 70 , y en 1977 tuvieron lugar las primeras reuniones programáticas de la Conferencia de Estudios Críticos del Derecho. Los estudios críticos del derecho apuntaban a una crítica radical de las instituciones jurídicas, fundada en la constatación de que el derecho se había convertido en un enemigo de la comunidad auténtica y empática. Como lo sostuvo Robert Gordon en un muy conocido trabajo pertinente a los estudios críticos del derecho, publicado el mismo año en que se fundó la Revista de Ética Profesional de Georgetown,

CLS [por su nombre en inglés: Critical Legal Studies] es un movimiento primordialmente de profesores de derecho, pero que incluye también abogados que ejercen, que para la mayoría de nosotros comienza a fines de los 60 o inicios de los 70 a partir de un descontento con el sistema de educación legal. Esperábamos producir

5 En el ámbito político, quizás el mejor ejemplo es la Declaración de Port Huron, el manifiesto fundante de los Estudiantes por una Sociedad Democrática: "El fin del hombre y de la sociedad debiera ser [...] la búsqueda de un significado en la vida que sea personalmente auténtico: una cualidad de la mente no compulsivamente motivada por un sentimiento de impotencia, ni por un sentimiento que irreflexivamente adopta valores establecidos. [...] Vínculos personales entre hombres son necesarios, en especial para ir más allá de los vínculos parciales y fragmentarios de las funciones, que unen a los hombres solo como trabajadores, empleadores y empleados, maestros y estudiantes, americanos y rusos". The Port Huron Statement of the Students for a Democratic Society (June 11-15, 1962), disponible en: http://coursesa.matrix.msu.edu/ hst306/ documents/huron.html. 
trabajos sobre el derecho que transmitieran de modo claro nuestro desasosiego, y que a partir de esos sentimientos incipientes de descontento surgiera una crítica con algo de contundencia y sustancia [...] Pero al mismo tiempo el movimiento persigue algunos objetivos políticos y sociales compartidos [...] [N]os une el deseo de que nuestro trabajo contribuya, en la medida de lo posible, a la realización del potencial que creemos existe para transformar las prácticas del sistema jurídico de modo de promover una sociedad más decente, igualitaria y solidaria -es decir, menos marcadamente estructurada sobre la base de jerarquías de clase, estatus, "mérito", raza, y género- más descentralizada, democrática y participativa, tanto en sus propias lógicas de vida social como en las formas que promueve en otros países ${ }^{6}$.

No es coincidencia que Gordon sea considerado uno de los más distinguidos especialistas en ética profesional, y que su trabajo The Independence of Lawyers esté dentro de los clásicos de esa literatura especializada ${ }^{7}$. Aun cuando relativamente pocos profesores universitarios de derecho y abogados se unieron a los estudios críticos del derecho, muchos simpatizaban con la corriente, y todavía muchos más simpatizaban con el discurso más general de los movimientos sociales ${ }^{8}$.

Vale la pena notar que el movimiento de educación clínica surgió en el mismo período de agitación social y demandas reformistas; y algunos de los más distinguidos pensadores de ética jurídica son, o comenzaron su carrera como, especialistas en la enseñanza clínica9 ${ }^{9}$ La íntima conexión entre la educación clínica y el desarrollo teórico de la ética profesional resulta fascinante, pero explicar las variadas complicaciones de este episodio histórico es materia de otro trabajo.

${ }^{6}$ Robert W. Gordon, "Unfreezing Legal Reality: Critical Approaches to Law", 15 Fla. St. U.L. Rev., pp. 195, 196-97 (1987).

${ }^{7}$ Robert W. Gordon, “The Independence of Lawyers”, 68 B. U. L. Rev., p. 1 (1988).

${ }^{8}$ Por ejemplo, a principios de los 1980, la Conferencia de Estudios Críticos del Derecho tuvo 350 participantes, mientras que la conferencia anual de 1982 tuvo 1.000 asistentes. Allan C. Hutchinson \& Patrick J. Monahan, "Law, Politics, and the Critical Legal Scholars: The Unfolding Drama of American Legal Thought”, 36 Stan. L. Rev., pp. 199, 201 (1984). De modo similar, nuestra impresión es que varios de los académicos cuyo trabajo aparece en la bibliografía de CLS de Kennedy y Klare del año 1984 (Duncan Kennedy \& Karl E. Klare, “A Bibliography of Critical Legal Studies”, 94 Yale L. J. 461 (1984)) se identificarían como simpatizantes del movimiento pero no necesariamente como "académicos de CLS". Entre estos incluiríamos a: Howard Lesnick, Carrie Menkel-Meadow, y Deborah L. Rhode; otros, como Richard Abel, Robert S. Gordon y William H. Simon, son más cercanos y se identifican directamente con los CLS. Uno de nosotros (Luban) se ubicaría en el grupo de los simpatizantes. Véase el ensayo principal de David Luban, Legal Modernism (1993). El otro suscrito (Wendel) conscientemente se identifica con movimientos pre-CLS, como la escuela del proceso legal. Véase, e.g., W. Bradley Wendel, The Craft of Legal Interpretation, en Interpretation of Law in the Age of Enlightenment: From the Rule of the King to the Rule of Law (Yasutomo Morigiwa, ed., 2011).

9 Son demasiados, de modo que no intentaremos nombrarlos. Solo mencionaremos algunos teóricos prominentes que comenzaron o que todavía ejercen en el ámbito clínico: Anthony Alfieri, Gary Bellow, Clark Cunningham, Kate Kruse, Peter Margulies, Carrie Menkel-Meadow, Abbe Smith, y Paul Tremblay. Una descripción clásica sobre los orígenes de la educación clínica es Michael Meltsner \& Philip G. Schrag, "Report from a CLEPR Colony”, 76 Colum. L. Rev. 581 (1976). 


\section{B. La crítica a la concepción "estándar" del partisano neutral}

Notablemente, dos de los académicos fundadores de la ética profesional teórica se identificaban con el movimiento social de izquierda del momento. Richard Wasserstrom, quien hoy tiene 80 años de edad, es filósofo, profesor de derecho, y un eminente abogado de libertades civiles (hoy retirado). En 1975 publicó un trabajo titulado Lawyers as Professionals: Some Moral Issues ${ }^{10}$, que inauguró la filosofía de la ética profesional moderna. A Wasserstrom le preocupaba constatar que el rol de la abogacía convertía “a los abogados, en el mejor de los casos, en personas sistemáticamente amorales, y en el peor de los casos, en personas más que ocasionalmente inmorales, en su trato con el resto de la humanidad"; y se preguntaba si la lealtad unilateral hacia el cliente podía ser reconciliada con la expectativa de universalidad del punto de vista moral. Recuérdese que Kant sostenía que todo ser humano, o más bien todo sujeto racional, debe ser tratado como un fin en sí mismo, y no solo como un medio para nuestros propios fines ${ }^{11}$. Por contraste, la función del abogado es tratar al cliente como un fin en sí mismo, pero a nadie más. Como lo afirman de modo brutal un par de autores: "Cuando alguien necesita ayuda en aquellos procesos en los que las personas son tratadas como instrumentos, no como fines, acude a los abogados, acude a nosotros"12. Luego agregan: "Entonces, si buscas una definición expresiva de lo que un abogado es, quizás esto sirva: un abogado es una persona que, representando a unos, trata a otros de la misma forma en que los burócratas tratan a todo el mundo -como no personas-" 13 . Ni siquiera Thomas Macaulay fue tan brutalmente directo.

Wasserstrom escribió en un tono más imparcial. Levantó preguntas difíciles y centrales del rol moral de los abogados, pero nunca afirmó tener la respuesta. Tenía muy claro que los roles sociales y las lealtades relacionales estaban profundamente arraigadas en la estructura de la ética humana. Considérese el rol social de un padre. Los padres favorecen el interés de sus propios hijos, por sobre los intereses de los hijos de otras personas, y sería extraño que la moral universal condenara ese tipo de favoritismo, que forma parte de la naturaleza humana. La moral universal reclama la atención de nuestra imaginación moral, pero también lo hacen los roles sociales. El punto es cómo reconciliar ambas exigencias ${ }^{14}$. Aunque Wasserstrom no solucionó el problema, el solo hecho de

105 Hum. Rts. 1 (1975).

${ }^{11}$ En Immanuel Kant, "Groundwork of the Metaphysics of Morals", en Practical Philosophy (The Cambridge Edition of the Works of Immanuel Kant) 79 (Mary J. Gregor ed. y trad., 1996), AK. 4:428.

12 Edward A. Dauer \& Arthur Allen Leff, "Correspondence: The Lawyer as Friend", 86 Yale L.J. 573, 581 (1977).

13 Idem.

14 Richard Wasserstrom, "Roles and Morality", en The Good Lawyer: Lawyers' Roles and Lawyers' Ethics 24, 26-27 (David Luban, ed., 1983). Véase también David LuBAN, Lawyers and Justice: An Ethical Study, pp. 105-16 (1988) (explorando la tensión entre una moral de roles y una moral que rechaza las exigencias de los roles). Otro trabajo pionero de ética profesional (y de ética de la profesión legal) que se concentra en problemas de ética del rol es Alan Goldman, The Moral Foundations of Professional Ethics (1980). Véase también Michael J. Kelly, Legal Ethics and Legal Education (Hastings Center, 1980). 
levantarlo resonó con los movimientos sociales del momento: puso en cuestión los roles establecidos sobre bases esencialmente éticas. Notoriamente, Lawyers as Professionals: Some Moral Issues también cuestionó el paternalismo de los abogados en su trato con los clientes; otro tema que se ha vuelto esencial en la discusión teórica respecto de ética profesional $^{15}$.

Tres años más tarde, William Simon, un joven profesor de derecho vinculado a los estudios críticos del derecho, publicó un brillante artículo de 100 páginas, titulado "The Ideology of Advocacy"16. El trabajo elaboraba una dura crítica a la ética profesional tradicional. Comenzaba ofreciendo la primera definición precisa de lo que se había estado denominando el modelo del "partisano neutral" o la "concepción estándar" de la ética profesional ${ }^{17}$. La concepción estándar, que era objeto de mucha atención por los filósofos en la incipiente literatura de ética profesional, incluye por lo general tres principios: (1) parcialidad -defender los intereses jurídicamente legítimos del cliente-; (2) neutralidad -no tomar partido por el mérito moral de los fines del cliente-; y (3) no responsabilidad -inmunidad a la crítica moral por asistir a otro a actuar inmoralmente- ${ }^{18}$. Simon revisó las principales teorías a favor de la concepción estándar -realismo jurídico, la teoría del proceso legal, y la defensa de la autonomía del cliente- y sostuvo que ninguna de ellas lograba su objetivo. También advirtió que rodear al derecho con una neblina de tecnicismos y misticismo solo accesible al experto (al abogado) produce el efecto de alienar al cliente del derecho. Así, los abogados suplantan la experiencia subjetiva del cliente con su propia comprensión de los problemas de los clientes. En lugar de la abogacía profesionalizada, Simon propuso avanzar hacia una suerte de desprofesionalización, en virtud de ello, las convicciones morales personales del abogado jueguen un rol central en la determinación del alcance de la representación de los intereses del cliente ${ }^{19}$. Años después, Simon abandonaría esta idea de desprofesionalización, pero en su momento

${ }^{15}$ Véase, por ejemplo, David Luban, "Paternalism and the Legal Profession", 1981 Wis. L. Rev. 454; Katherine R. Kruse, "Beyond Cardboard Clients in Legal Ethics", 23 Geo. J. Legal Ethics 103 (2010).

${ }^{16}$ William H. Simon, “The Ideology of Advocacy: Procedural Justice and Professional Ethics”, 1978 Wis. L. Rev. 29.

${ }^{17}$ Ibid., pp. at 36-37. Murray Schwartz ofreció una definición similar coincidiendo con Simon. Véase Murray L. Schwartz, "The Professionalism and Accountability of Lawyers”, 66 Cal. L. Rev. 669, 673 (1978). La diferencia principal radica en que mientras Simon puso énfasis en el Principio de Neutralidad, Schwartz puso énfasis en el Principio de No Responsabilidad Moral. Hasta donde llega nuestro conocimiento, la etiqueta "concepción estándar de la ética profesional” proviene de GerAld J. Postema, "Moral Responsibility in Professional Ethics”, 55 N.Y.U. L. Rev. 63, 73 (1980) -otra contribución pionera de la primera oleada. Pero véase Ted Schneyer, “Moral Philosophy’s Standard Misconception of Legal Ethics”, 1984 Wis. L. Rev. 1529 (afirmando que no hay nada "estándar" en la así llamada "concepción estándar", del modo en que los filósofos morales la entienden).

${ }^{18}$ Véase, e.g., Tim Dare, The Counsel of Rogues? A Defence of the Standard Conception of the Lawyer's Role, pp. 5-12 (2009). Como se hizo notar más arriba (nota 17), distintos académicos ofrecieron formulaciones diferentes para el modelo del partisano neutral: Simon puso el énfasis en la neutralidad antes que en la no responsabilidad.

${ }^{19}$ Simon, "Ideology" (nota 16), pp. 130-42. 
parecía una idea prometedora ${ }^{20}$. Wasserstrom también flirteó con un modelo desprofesionalizado del rol del abogado ${ }^{21}$. En este sentido, entonces, podemos decir que ambos se sintieron atraídos por la crítica contracultural al conformismo.

En torno a los temas que Wasserstrom, Simon, y algunos otros levantaron se produjo un flujo considerable de contribuciones. Esto es lo que aquí llamaremos la "primera oleada" de literatura académica de ética profesional. Uno de los autores del presente artículo (Luban) se considera con orgullo un miembro de esta primera oleada, y puede reportar que participar en esta discusión fue muy fascinante. Se percibió como un momento de descubrimiento - un momento en el que se estaba logrando un progreso intelectual genuino en torno a las cuestiones más profundas de la filosofía jurídica y moral- ${ }^{22}$. En vez de formular preguntas abstractas y conceptuales, los académicos estaban estudiando la práctica de los abogados, y parecía que esa era la dirección correcta. Todavía parece que es así. Deborah Rhode, profesora de derecho de Stanford, y también una influyente académica de la primera oleada, combinó aproximaciones teóricas con sofisticados análisis multidisciplinarios de asuntos regulatorios, como por ejemplo la exigencia de buena conducta de la barra, o la prohibición de ejercicio no autorizado de la profesión ${ }^{23}$. También atendió las necesidades institucionales de esta emergente disciplina, en la forma de manuales de enseñanza, centros profesionales y la formación de instructores jóvenes. Rhode, junto con Carrie Menkel-Meadow, fueron también las primeras en introducir una perspectiva explícitamente feminista a la ética profesional ${ }^{24}$. David Wilkins, de la Escuela de Derecho de Harvard, situó la ética profesional en el contexto más general de la teoría del derecho norteamericana, incluyendo las escuelas de análisis económico del derecho, del proceso legal, y las corrientes de realismo legal ${ }^{25}$. Wilkins también formuló preguntas cruciales de las conexiones entre el rol profesional y la raza -preguntándose, por ejemplo, si un abogado de raza negra podía permitirse,

${ }^{20}$ Véase William H. Simon, The Practice of Justice (1998); Robert W. Gordon \& William H. Simon, “The Redemption of Professionalism?", en Lawyers' Idelas/Lawyers' Practices: Transformations in the American Legal Profession 230 (Robert L. Nelson, et al., eds. 1992). Para una temprana crítica a la desprofesionalización véase Postema (nota 17), pp. 71-73.

${ }^{21}$ Richard Wasserstrom, "Lawyers as Professionals: Some Moral Issues" (nota 10), pp. 22-24.

${ }^{22}$ La contribución más importante de Luban a la primera oleada es su Lawyers and Justice: An Etbical Study (1988).

${ }^{23}$ Véase, e.g., Deborah L. Rhode, "Moral Character as a Professional Credential", 94 Yale L.J. 491 (1985); Deborah L. Rhode, "Policing the Professional Monopoly: A Constitutional and Empirical Analysis of Unauthorized Practice Prohibitions”, 34 Stan. L. Rev. 1 (1981). Para otras contribuciones teóricas, véase, e.g., Deborah L. Rhode, "Ethical Perspectives on Legal Practice", 37 Stan. L Rev. 589 (1985); Deborah L. Rhode, In the Interest of Justice (2000).

${ }^{24}$ Deborah L. Rhode, "Perspectives on Professional Women”, 40 Stan. L. Rev. 1163 (1988); Carrie Menkel-Meadow, "Portia in a Different Voice: Speculations on a Women's Lawyering Process", 1 Berkeley Women's L.J. 39 (1985). Véase, en un marco más general, Katharine T. Bartlett, "Feminist Legal Methods”, 103 Harv. L. Rev. 829 (1990).

${ }^{25}$ Véase David B. Wilkins, “Who Should Regulate Lawyers?”, 105 Harv. L. Rev. 801 (1992); David B. Wilkins, "Legal Realism for Lawyers”, 104 Harv. L. Rev. 468 (1990). 
moralmente hablando, representar al Ku Klux Klan- ${ }^{26}$ (esta conexión entre raza y el rol del abogado fue desarrollada antes por Anthony Alfieri en muchas publicaciones) ${ }^{27}$.

También durante la primera oleada aparecieron académicos religiosamente comprometidos, sobresaliendo entre ellos Thomas Shaffer, quien se preguntó por las obligaciones de los abogados católicos ${ }^{28}$ (académicos de la cultura judía también hicieron contribuciones similares ${ }^{29}$. Un abogado católico en particular podría cuestionarse que sea posible ejercer como abogado sin contribuir necesariamente a la decadencia de todas las instituciones humanas, incluyendo el derecho ${ }^{30}$. Debido a que las respuestas a estas preguntas dependen de ciertos compromisos teológicos, la influencia de esta literatura, de abogacía religiosamente comprometida, fue limitada. Su impacto en círculos más amplios dependería de que fuera traducida a lo que Rawls denominó "razones públicas”, corriendo el riesgo de perder su distintiva voz profética ${ }^{31}$.

Shaffer, podríamos agregar, no proviene del entorno progresista y contracultural que antes señalamos como inspiración de la primera oleada. Él fue decano de la Escuela de Derecho de Notre Dame, y aquellos que han leído su artículo de 1971 defendiendo los derechos de propiedad en contra del "sesgo liberal", o su crítica feroz a la democracia liberal, puede que lo confundan con el abogado-caballeresco conservador del que escribe a

${ }^{26}$ David B. Wilkins, "Race, Ethics, and the First Amendment: Should a Black Lawyer Represent the Ku Klux Klan?”, 63 G.W. L. Rev. 1030 (1995). Véase también David B. Wilkins, "Two Paths to the Mountaintop? The Role of Legal Education in Shaping the Values of Black Corporate Lawyers", 46 Stan. L. Rev. 1981 (1993). Naturalmente, el hecho de que, en el mundo de la academia legal, los académicos jóvenes de Harvard y Stanford se identificaran a sí mismos como eticistas legales al inicio de sus carreras resultó de crucial importancia para la legitimidad del campo.

${ }^{27}$ Aprovechando la ocasión de la conmemoración de la Revista de Georgetown en que se incluye la presente contribución, citamos aquí dos artículos de su autoría que aparecieron antes en este medio: ANTHONY V. Alfieri, "Objecting to Race”, 27 Geo. J. Legal Etbics 1129 (2014); Alfieri, "Speaking Out of Turn: The Story of Josephine V.”, 4 Geo. J. Legal Ethics 619 (1991).

${ }^{28}$ Véase, e.g., Thomas L. Shaffer, On Being a Christian and a Lawyer (1981); Thomas L. Shaffer, "Faith Tends to Subvert Legal Order", 66 Fordham L. Rev. 1089 (1998); Thomas L. Shaffer, "The Legal Ethics of Radical Individualism”, 65 Tex. L. Rev. 963 (1987). Véase también Howard LeSNick, "No Other Gods: Answering the Call of Faith in the Practice of Law", 18 J. L. E Relig. 458 (2002). Para una notable contribución reciente a la literatura sobre abogacía y religión: Robert K. Vischer, Martin Luther King Jr. And the Morality of Legal Practice: Lessons in Love and Justice (2013).

${ }^{29}$ E.g., Russell G. Pearce, "To Save a Life: Why a Lawyer and a Rabbi Must Disclose a Confidence”, 29 Loyola L.A. L. Rev. 1771 (1996); SANFORD Levinson, "Identifying the Jewish Lawyer: Reflections on the Construction of Professional Identity”, 14 Cardozo L. Rev. 1577 (1993); David Luban, “A Midrash on Rabbi Shaffer and Rabbi Trollope”, 77 Notre Dame L. Rev. 889 (2002), reimpreso en David Luban, Legal Ethics and Human Dignity 301 (2007); AввE Smith \& William Montross, "The Calling of Criminal Defense”, 50 Mercer L. Rev. 443 (1999).

${ }^{30}$ Véase, e.g., Milner S. BALl, “A Meditation on Vocation”, en Radical Christian and Exemplary Lawyer: Honoring William Stringfellow 130 (Andrew W. McThenia, Jr., ed., 1995); véase también STANLEy HaUERWAS, After Christendom?: How the Church is to Behave if Freedom, Justice, and a Christian Nation are Bad Ideas (1991).

${ }^{31}$ Shaffer, quien fue muy influenciado por el teólogo Menonita John Howard Yoder, advierte a abogados religiosamente comprometidos que comportarse como profeta puede llevar a que otros te vean como un loco: Thomas L. Shaffer, "On Being a Professional Elder”, 62 Notre Dame L. Rev. 624, 640 (1987). 
menudo ${ }^{32}$. No obstante, Shaffer (que se describe a sí mismo como "de centro-izquierda", y critica la inclinación patriarcal del abogado-caballeresco $)^{33}$ ha llegado a identificarse de modo explícito con las corrientes más radicales del cristianismo, una especie de cristianismo de los evangelios que el mismo Shaffer describe como "contracultural" y que prescribe un igualitarismo económico, oposición al poder coercitivo, y desconfianza del patriotismo como idolatría ${ }^{34}$. Su visión de la ética profesional es igualmente radical: vislumbra abogados entablando relaciones ministeriales con sus clientes, las que describe de manera aterradora como sigue:

La escena que se superpone a la celda donde sostenemos conversaciones con los culpables es la de Jesús y los colectores de impuestos. La escena que se superpone a la horrorosa imagen de mi cliente recibiendo su castigo es la de Dimas en la cruz, Dimas con un abogado y un camarada colgando a su lado ${ }^{35}$.

En lo que respecta al modelo de partisano neutral, Shaffler lo identifica irónicamente como la "singular, original y endeble ética adversarial" 36.

\section{Defensas a una concepción (más o menos) estándar}

No todos los participantes de la primera oleada de ética profesional filosófica eran críticos de la concepción estándar. La idea tradicional de la abogacía también tenía defensores. Una primera y muy original defensa fue formulada por Charles Fried, quien acuñó la metáfora del "abogado como amigo" 37 . Fried sostuvo que el abogado era como un amigo especial del cliente. La moral autoriza que privilegiemos a nuestros amigos por sobre otras personas, siempre y cuando no violemos los derechos de terceros. Ciertas relaciones humanas - paradigmáticamente, entre familiares y amigos- se vuelven elementos importantes y constitutivos de la vida de una persona. Se sigue de esto que la moral nos permite privilegiar los intereses de aquellos con quienes cultivamos relaciones cercanas y personales, en contraste con el compromiso que podemos tener con el bienestar de la humanidad como un todo. Como amigo del cliente, el abogado asume los intereses del cliente como propios, ya que eso forma parte de la definición clásica de una amistad ${ }^{38}$. Todavía más, debido a que el abogado opera en el contexto de un sistema jurídico, no

32 Thomas L. Shaffer, "Men and Things: The Liberal Bias Against Property", 57 Abaj 123 (1971); Thomas L. Shaffer \& Mary Shaffer, American Lawyers and their Communities: Etbics in the Legal Profession, 13, 24 (1991).

33 Ibid., p. 36 n. 1; pp. 51-58.

34 Thomas L. Shaffer, “Should a Christian Sign Up for Simon's Practice of Justice?", 51 Stan. L. Rev., 903, 907-910 (1999).

${ }^{35}$ ShafFer, On Being a Christian and a Lawyer (nota 28), p. 79.

36 Thomas L. Shaffer, "The Unique, Novel, and Unsound Adversary Ethic”, 41 Vand. L. Rev., 697 (1988).

37 Charles Fried, "The Lawyer as Friend: The Moral Foundations of the Lawyer-Client Relation”, 85 Yale L.J., 1060 (1976).

${ }^{38}$ Ibid., p. 1071. 
es directamente responsable de las consecuencias que el sistema produzca -“cualquier injusto es puramente institucional" afirma Fried- ${ }^{39}$. No es un injusto imputable al abogado. Como dice el refrán, "no odies al jugador, odia al juego".

En respuesta, los críticos de Fried sostuvieron que la conclusión que se extraía de la analogía del "abogado como amigo" era errada. Uno de ellos argumentó que, al adoptar los intereses de un amigo como propios, uno asume responsabilidad moral por ellos ${ }^{40}$. Simon fue más lejos en su crítica a Fried. Poniendo el énfasis en la transacción patrimonial de la que se favorecía el abogado al hacerse amigo del cliente, Simon ironizó que Fried no estaba tratando con la noción clásica de amistad, sino con la de prostitución ${ }^{41}$.

Para Dauer y Leff la concepción que Fried tiene de la amistad -adoptar los intereses del amigo como propios- captura una parte muy pequeña de lo que la amistad representa, y concluyen que "un abogado es como un amigo [...] porque, para el profesor Fried, un amigo es como un abogado" ${ }^{2}$. No obstante estas críticas, muchos abogados siguen considerando atractiva la idea de Fried, porque se corresponde con la auténtica experiencia de representar clientes. Uno de nosotros (Luban), lo ha presenciado numerosas veces en los estudiantes de clínicas; por ejemplo, aquellos que representan personas de escasos recursos buscando asilo político, o mujeres víctimas de violencia intrafamiliar. Los estudiantes a menudo se involucran intensamente en las vidas de sus clientes, tanto así que muchas veces les corresponde a los profesores recordarles la importancia de mantener los límites. Son genuinos amigos, en tanto abogados, aunque es posible que este no sea el sentido que tenía en mente Fried.

Otra poderosa defensa de la concepción estándar pone el énfasis en el reforzamiento de la autonomía del cliente, que hace posible el abogado ${ }^{43}$. Una persona autónoma elige sus propios fines. El rol del abogado consiste en ayudar al cliente a perseguir aquellos fines a los que tienen legítimo derecho; es decir, a perseguir fines dentro de los límites jurídicos, aun si el abogado estime que se trata de fines reprobables. Asistir a los clientes de este modo es una tarea esencial en un estado de derecho, porque el derecho es opaco y difícil de entender para el lego. Lo que hace el abogado es permitir al cliente ejercer cursos de acción elegidos por él o ella de modo autónomo, y jurídicamente permitidos. Esta es ciertamente una noble vocación.

Monroe Freedman dotó al argumento de la autonomía de bases constitucionales ${ }^{44}$. Debido a que dispuso de la Constitución de Estados Unidos para construir su argumento,

\footnotetext{
${ }^{39}$ Ibid., p. 1085.

${ }^{40}$ SusAn WOLF, "Ethics, Legal Ethics, and the Ethics of Law", en The Good Lawyer (nota 14), p. 59 n.4

41 Simon, "The Ideology of Advocacy" (nota 16), p. 108.

42 DAUer \& LefF (nota 12), p. 578.

43 Este argumento es articulado convincentemente en Stephen L. Pepper, "The Lawyer's Amoral Ethical Role: A Defense, A Problem, and Some Possibilities”, 1986 Am. B. Found. Res. J. 613.

${ }^{44}$ Véase, e.g., Monroe L. Freedman, Lawyers' Ethics in an Adversary System (1975). Freedman, en coautoría con Abbe Smith, preparó luego un manual de estudio que contiene una defensa bien elaborada a la idea de que el rol fundamental del abogado es defender y promover los derechos constitucionales del individuo frente al Estado. Véase Monroe Freedman \& Abbe Smith, Understanding Lawyers' Etbics (5ta ed. 2016).
} 
esto pudo haber limitado la influencia de su trabajo internacionalmente, pero de todas formas resonó poderosamente en el mundo de los abogados, en particular en los abogados dedicados a la defensa penal. Para Freedman, la permisiva ética del celo adversarial del defensor penal se funda en el derecho al debido proceso de la quinta enmienda de la Constitución de Estados Unidos, y en el derecho a la defensa de la sexta enmienda (y, en último término, en la inmunidad individual frente a la intervención estatal que subyace a ambos derechos). En su célebre artículo de las "tres preguntas más difíciles" de responder para los defensores penales, Freedman sostuvo que los deberes para con el cliente -confidencialidad y defensa empeñosa- debieran tener prioridad frente al deber de honradez para con el tribunal. Los abogados, entonces, debieran permitirle a sus clientes cometer perjurio ${ }^{45}$. Esta posición fue tan controversial que el entonces juez presidente de la Corte de Apelaciones del Octavo Distrito Warren Burger, junto con otros jueces federales, formularon quejas disciplinarias contra Freedman ${ }^{46}$. Pero Freedman nunca se apartó de su tesis de que, en caso de colisionar las obligaciones del abogado, el deber que toma precedencia es el deber hacia el cliente ${ }^{47}$. Abbe Smith, coautora junto con Freedman de Understanding Lawyers' Ethics, ha ofrecido argumentos igualmente poderosos a favor de esta caracterización del rol del defensor penal, aunque ella no los fundamenta solo en derechos de autonomía sino también en una crítica al sistema de justicia penal ${ }^{48}$.

El argumento de la autonomía es poderoso, pero en nuestra opinión no es decisivo ${ }^{49}$. Para ver por qué (y como un breve paréntesis en nuestra narración histórica), consideremos un conocido caso, ampliamente discutido en la literatura de ética profesional: el caso Dalkon Shield respecto de responsabilidad por uso de un dispositivo intrauterino ${ }^{50}$. El dispositivo provocó infecciones que dejaron estériles a miles de mujeres. Aunque el juicio se centró en la pregunta de si el producto era defectuoso, la defensa sugirió que

45 Véase Monroe H. Freedman, "Professional Responsibility of the Criminal Defense Lawyer: The Three Hardest Questions”, 64 Mich. L. Rev. 1469 (1966). Las otras dos preguntas difíciles se refieren a: (i) el contraexamen agresivo del testigo de la contraparte, quien según le consta al abogado está diciendo la verdad; y (ii) la cuestión de cómo explicar el derecho al cliente, sabiendo que este acomodará luego su historia para poder invocar excepciones y defensas.

46 Véase Monroe H. Freedman, "Getting Honest About Client Perjury", 21 Geo. J. Legal Ethics 133 (2008).

47 En algún sentido, el Juez Berger terminó venciendo: él redactó la opinión unánime en Nix $v$. Whiteside, 475 U.S. 157 (1986), donde la Corte Suprema Federal sostuvo que un abogado que le hace saber a su cliente que informará al tribunal respecto del perjurio cometido por el cliente no viola los derechos fundamentales de la Sexta Enmienda.

48 Véase en general Monroe Freedman \& AbBe Smith, Understanding Lawyers' Ethics (4ta ed., 2010); Aвве Smith, "Defending Defending: The Case for Unmitigated Zeal on Behalf of People Who Do Terrible Things", 28, Hofstra L. Rev. 925 (2000).

49 Véase David Luban, “The Lysistratian Prerogative: A Response to Stephen Pepper”, 1986 ABF Res. J. 637; LubAn, "Partisanship, Betrayal, and Autonomy in the Lawyer-Client Relationship: A Reply to Stephen Ellmann”, 90 Colum. L. Rev. 1004, 1035-43 (1990).

${ }^{50}$ Véase W. Bradley Wendel, Lawyers and Fidelity to Law, pp. 24-26 (2010); David Luban, "The Adversary System Excuse", en Legal Ethics and Human Dignity, pp. 35 -36 (2007); Deborah L. Rhode, Ethics by the Pervasive Method, p. 669 (1984). 
una explicación causal alternativa para la condición de inflamación pélvica sufrida por las demandantes podía encontrarse en ciertas prácticas sexuales y de higiene. Para defender su caso, los abogados de la empresa elaboraron una estrategia brutal pero efectiva, que llegó a ser conocida como la "lista de las preguntas sucias". Durante el proceso de descubrimiento de pruebas previo al juicio, formularon a las mujeres preguntas gráficas e incluso humillantes como: “¿qué tan seguido practicabas sexo anal?” y "cuando usas el baño, ¿te limpias desde atrás hacia adelante?”. También les solicitaron los nombres y dirección de todas sus parejas sexuales "distintas de su marido", probablemente para poder formular a esas personas las mismas preguntas íntimas. Los abogados sostuvieron que las "preguntas sucias" eran relevantes para la cuestión jurídica de la causalidad, porque podían dar cuenta de otros posibles orígenes de la infección pélvica. Lamentablemente, el juez accedió y permitió las preguntas.

Lo cierto es que todo el mundo entendió que el verdadero propósito era intimidar a las mujeres, advertirles que si seguían adelante con sus demandas podían ser humilladas por tener que responder las "preguntas sucias" en un juicio público. Una de las mujeres reclamó que las preguntas eran "como una llamada telefónica obscena" 51 . Respondió de todas formas las preguntas, pero muchas otras mujeres abandonaron las causas, que era precisamente lo que buscaba la empresa -es decir, la estrategia de intimidación de los abogados fue exitosa-. Los abogados de la defensa tomaron la decisión consciente de asistir a su cliente usando la estrategia de las "preguntas sucias". ¿Por qué debieran ser liberados de reproche moral por decidir autónomamente dañar y humillar a mujeres perjudicadas? Ellos responderían indignados: “¡No! lo único que estaba haciendo era defender la autonomía de mi cliente”. Pero eso no es lo único que estaban haciendo. La "lista de preguntas sucias" hizo dos cosas: defendió la autonomía del cliente y también dañó y humilló a un inocente. No se puede optar por describir la mitad de un hecho y dejar fuera la otra mitad. De hecho, la táctica de intimidación de las "preguntas sucias" defendió la autonomía del cliente por la vía de humillar a personas inocentes, de modo que las dos partes de la descripción del hecho van unidas como carne y hueso.

La cuestión de si las descripciones de los actos realizados en ejercicio de la función de abogado pueden traducirse a descripciones ordinarias es una cuestión fundamental en la ética profesional. Después de todo, hay una gran diferencia entre usar un cuchillo en una pelea callejera y en una sala de operación; en un caso es para mutilar, en el otro para operar. La cuestión en particular es objeto de análisis en un importante trabajo de ética profesional: Ethics for Adversaries de Arthur Applbaum ${ }^{52}$. Existen múltiples des-

51 Ronald J. BACIGaL, The Limits of Litigation: The Dalkon Shield Controversy, pp. 19-20 (1990).

52 Arthur Isak Applbaum, Ethics for Adversaries: The Morality of Roles in Public and Professional Life (1999). El capítulo que interesa fue publicado originalmente como ArTHur IsAK Applbaum, "Are Lawyers Liars? The Argument of Redescription”, 4 Legal Theory 63 (1998). Para otras contribuciones destacadas respecto de ética del rol de filósofos morales (externos a la academia legal), véase Alan Goldman, The Moral Foundations of Professional Ethics 1-33, 90-155 (1980); Alan GEwIRTH, "Professional Ethics: The Separatist Thesis", 96 Ethics 282 (1986); Michael Hardimon, "Role Obligations", 91 J. Phil. 333 (1994); Judith Andre, "Role Morality as a Complex Instance of Ordinary Morality", 28 Am. Phil. Q. 73 (1991); Mike W. Martin, "Rights and the Meta-Ethics of Professional Morality”, 91 Ethics 619 (1981). 
cripciones posibles para el interrogatorio del caso Dalkon Shield, incluyendo: un hombre haciendo preguntas intrusivas y perturbadoras pertinentes a las prácticas sexuales de un extraño; un hombre tratando de intimidar a una víctima para evitar que demande una indemnización; o, un abogado buscando pruebas para respaldar una defensa en un juicio civil. ¿Cuál de estas es la descripción apropiada? Sabemos, del trabajo de John Searle y de otros, que las prácticas sociales en que se sitúan las acciones pueden cambiar la descripción de las mismas ${ }^{53}$. Así, ciertos actos como "llegar a primera base" solo son posibles dentro de la práctica social del béisbol. No obstante, argumenta Applbaum, la posibilidad de describir un acto institucional, como "tomar una declaración", no borra mágicamente la descripción del acto en términos ordinarios, como "hacer preguntas sucias" o "humillar a un extraño" -así como tampoco la expresión "hacer un home run" reemplaza la descripción "romper una ventana con una bola" cuando, jugando en un terreno vacío un jugador manda una bola demasiado lejos- ${ }^{54}$.

El caso Dalkon Shield revela otro problema del argumento de la autonomía. En este caso el demandado no era una persona natural sino una corporación. Podemos estar de acuerdo con Kant en que la decisión autónoma es la facultad humana más elevada, la fuente de la dignidad humana. Pero no puede decirse lo mismo de una corporación, que es una persona jurídica, no una persona moral, y que por tanto no tiene dignidad humana ${ }^{55}$. Sus directores tienen autonomía moral, pero no son ellos los clientes del

53 John R. SEARLe, The Construction of Social Reality (1995).

54 Applbaum (nota 52), pp. 91-98.

55 Una corporación puede actuar, pero no asume responsabilidad moral por sus acciones. Véase DAVID Luban, Torture, Power, and Law, p. 291 (2014) (atribuyendo esta clarificación a Amy Sepinwall). Luban reconoce que su argumento nunca ha recibido demasiado apoyo: En mi libro Lawyers and Justice, sostuve que el privilegio abogado-cliente organizacional debería ser abolido, porque los clientes corporativos no son titulares de dignidad humana, y reconocerles privilegio implica un daño considerable a la sociedad pues facilita el encubrimiento de acciones corporativas. Este argumento, que ingenuamente pensé era uno de los más fuertes de ese libro, no generó ninguna crítica o discusión posterior. Aparentemente mi propuesta era demasiado imaginativa como para ser tomada en serio. DAvid Luban, "Lawyers as Upholders of Human Dignity (When They Aren't Busy Assaulting It)", en Legal Ethics and Human Dignity, pp. 65, 87 (2007). El silencio se puede explicar por el hecho de que para los abogados el privilegio de secreto abogado-cliente no tiene mucha relación con la dignidad, mucho menos en contextos corporativos. Como lo estableció la Corte Suprema Federal en Upjohn v. United States, 449 U.S. 383 (1981), el propósito del privilegio es permitir un flujo desinhibido de información confidencial entre abogado y cliente, de modo que el abogado pueda hacerse de toda la información relevante para asesorar al cliente respecto de sus obligaciones jurídica. Norman Spaulding ha desarrollado una crítica histórica y normativa de Upjobn, afirmando que la función del privilegio es reforzar una división moral del trabajo; abogado y cliente pueden deliberar en un espacio de confidencialidad respecto de la legalidad de cierto curso de acción, para que el cliente pueda luego tomar una decisión respecto de obedecer o no el derecho. Véase Norman W. SPaulding, "The Privilege of Probity: Forgotten Foundations of the Attorney-Client Privilege" 26 Geo. J. Legla Ethics 301 (2013); Norman W. Spaulding, "Compliance, Creative Deviance, and Resistance to Law: A Theory of the Attorney-Client Privilege”, 2013 J. Prof'l Lawyer 135. Esta puede ser una variante interesante del argumento dignitario respecto del privilegio corporativo, que podría servir para reforzar la responsabilidad moral y jurídica de directores corporativos. 
abogado $^{56}$. Parece, entonces, que el argumento de la autonomía pierde fuerza cuando el cliente es una organización.

En la primera oleada resalta un tercer argumento en defensa de la concepción estándar, cuyos orígenes se encuentran en la estructura adversarial de adjudicación. El juicio adversarial se presenta como la mejor forma de llegar a la verdad, y la abogacía partisana a su vez se presenta como el mejor mecanismo para defender los derechos individuales. Al menos ese es el argumento. Si los abogados partisanos son instrumentos esenciales tanto para encontrar la verdad como para defender derechos, ¿no debiera eso bastar para justificar el rol del abogado? Monroe Freedman defendió esta línea argumental en su Lawyers' Ethics in an Adversary System de 1975, pero la idea se remonta a un informe cuasioficial escrito en coautoría por John D. Randall y el gran filósofo del derecho Lon Fuller, de 1958 (que podría decirse es el primer artículo teórico de ética profesional de la era moderna $)^{57}$. Uno de nosotros denominó a este argumento la "excusa adversarial", y en una contribución temprana lo presentó como (apenas) una justificación pragmática débil para el comportamiento de los abogados ${ }^{58}$. El problema con la excusa adversarial es que funciona en la misma medida en que funciona el sistema adversarial mismo, que de por sí es un sistema imperfecto para buscar la verdad y defender derechos. La lógica adversarial funciona mejor cuando los abogados discuten cuestiones de derecho, no cuestiones de hecho. Cuando los jueces deciden cuestiones de derecho, observar a ambas partes del pleito alegar enérgicamente su caso ciertamente ayuda a decidir inteligentemente. Cuando se trata de argumentos puramente jurídicos no hay confidencias o secretos que guardar ni testigos que examinar; en otras palabras, lo que tenemos es una relativamente depurada dialéctica de argumentos.

Pero todo cambia cuando se trata de cuestiones de hecho. Aquí el trabajo del abogado es proteger los secretos del cliente y levantar dudas en torno a la prueba presentada por la contraparte -aun cuando el abogado sepa que la verdad está del otro lado-. ¿Puede un sistema así diseñado hacer un buen trabajo en la búsqueda de la verdad? Hay razones para dudarlo. Los mejores esfuerzos empíricos para abordar esta cuestión no han sido concluyentes, por una razón muy obvia: cuando un sistema esconde la verdad, esta permanece oculta, como un tesoro enterrado. De modo que nunca estaremos en una posición de afirmar que "el sistema falla en $5 \%$ (o en $10 \%$ o lo que sea)". ¿Cómo podemos saber? Considérese este argumento de sentido común. Supongamos que enfrentamos una decisión crucial, por ejemplo, la elección entre dos igualmente atractivas pero muy diferentes ofertas de trabajo. Si el sistema adversarial es realmente el mejor método para encontrar la verdad, preguntaríamos a nuestros amigos, o contrataríamos abogados, o investigaríamos todas las posibilidades disponibles, y usaríamos todos los trucos de los

${ }^{56}$ Model Rules of Prof'l Conduct: Rule 1.13(a).

${ }^{57}$ Lon Fuller \& John D. Randall, "Professional Responsibility: Report of the Joint Conference of the ABA-AALS", 44 ABA J., 1159 (1958).

58 David Luban, "The Adversary System Excuse”, en The Good Lawyer, 83 (David Luban, ed., 1983). Luban revisó y corrigió este ensayo, y referiría al lector a la versión definitiva, en Legal Ethics and Human Dignity, 19 (2007). 
litigantes para tratar de persuadirnos en favor de una opción -trucos que podrían incluir la supresión de información importante-. El, eufemísticamente denominado, proceso de descubrimiento de pruebas [discovery] de los juicios civiles puede ser objeto de abuso por los abogados cuando levantan objeciones frívolas o invocan privilegios, restringiendo artificialmente el espectro de información disponible, y enterrando documentos importantes en miles de páginas de basura ${ }^{59}$. Obviamente ninguna persona sensata tomaría una decisión crucial siguiendo esta perversa estrategia. De este modo, cualquiera sea el alcance de la autorización que tienen los abogados para adoptar una postura altamente partisana al discutir cuestiones legales, pareciera ser que en la ponderación de hechos vendría mejor una postura de neutralidad ${ }^{60}$.

Resumimos las tesis de la primera oleada en cuatro puntos:

(1) La ética profesional no es solo una cuestión de doctrina jurídica; en su nivel más elemental es parte integral de la filosofía moral.

(2) La principal pregunta a responder, respecto de la profesión de abogado, es cómo conciliar la ética del rol con la moral "ordinaria" o "común”, cuando entran en conflicto.

(3) La ética del rol se desarrolla en la, así llamada, concepción "estándar”, según esta, el abogado debe celosamente defender los intereses legítimos del cliente, a la vez que mantiene neutralidad moral frente a esos fines y frente a los medios jurídicamente legítimos para alcanzarlos. Para esta concepción el abogado es también inmune a reproches por cualquier "daño colateral" que pueda causar con su representación.

(4) Las tesis de la ética del rol giran en torno a la importancia moral de la relación abogado-cliente, el valor de la autonomía del cliente, y la importancia del sistema adversarial.

\section{LA SEGUNDA OLEADA: DE LA FILOSOFÍA MORAL A LA FILOSOFÍA POLÍTICA}

\section{Lo elemental de la segunda oleada: el rol del abogado en una democracia pluralista}

Las discusiones continuaron durante la primera oleada, y el debate sigue hasta la actualidad. Pero el tiempo pasa, y las mentes cambian. En las últimas dos décadas una nueva generación de académicos ha entrado al foro, y han llevado la disciplina a una

59 Véase, e.g., Robert L. Nelson, "The Discovery Process As a Circle of Blame: Institutional, Professional, and Socio-Economic Factors That Contribute to Unreasonable, Inefficient, and Amoral Behavior in Corporate Litigation", 67 Fordham L. Rev., 773 (1998).

${ }^{60}$ Véase, e.g., W. Bradley Wendel, "Whose Truth? Objective and Subjective Perspectives on Truthfulness in Advocacy”, 28 Yale J. L. E Human., 105 (2016). 
nueva dimensión ${ }^{61}$. Esta generación sostiene que la pregunta que preocupó a la primera oleada - ¿cómo puede conciliarse la ética del rol con la moral universal? (o, como lo planteó Fried, “¿puede un abogado ser una buena persona?”) ${ }^{62}$ - es simplemente la pregunta incorrecta. Sugiere que la ética profesional es una disciplina dependiente de la filosofía moral. Pero ocurre que el rol de abogado no es realmente un aspecto de la vida moral ordinaria, como el rol de padre o de vecino. Es un rol esencialmente institucional: es parte de un esquema de instituciones políticas y prácticas cuyo fin es la administración de la vida en comunidad. Hacer la analogía con la amistad, como lo hizo Fried, esconde el hecho de que el sistema jurídico es impersonal y burocrático, de un modo en que la amistad no lo es. Los críticos de Fried vieron en esto un error fatal de su analogía, y puede que lo sea, pero también puede constituir el punto de partida para una perspectiva normativa diferente del rol de abogado. La diferencia entre la amistad a secas y la amistad política "con fines especiales" es de hecho uno de los puntos que motivó a esta segunda oleada de ética profesional teórica.

La concepción de la segunda oleada comienza desde el objeto político del sistema jurídico en condiciones de pluralismo social. Con esto nos referimos a una sociedad que presenta convicciones morales y religiosas diversas, que a veces compiten. En esta sociedad se deben adoptar decisiones concretas acerca de una amplia gama de materias de importancia para la comunidad, y sin embargo los ciudadanos tienen desacuerdos respecto de lo que constituye una buena vida, qué fines es valioso perseguir, y qué elementos fácticos deben tenerse en consideración para resolver estas controversias. Una sociedad como esta enfrenta lo que Rawls denominó las "cargas del juicio" 63 . Si el pluralismo significa algo, como mínimo, es que no podemos esperar acuerdo entre los juicios racionales de las personas, aunque sean juicios elementales -por eso se dice que el juicio implica una "carga", en el sentido de que las razones o la racionalidad no permite arribar a respuestas únicas en cuestiones polémicas-.

En cuestiones de responsabilidad por el producto, o protección del consumidor, por ejemplo, podemos imaginar varias comprensiones (todas razonables, aunque en conflicto entre sí) de la responsabilidad que el fabricante de un producto tiene por el bienestar de los consumidores, en razón del beneficio que el producto les reporta a esos consumidores, y los riesgos a los que están expuestos en el uso del producto. El punto es que debe existir un piso mínimo para que fabricantes y consumidores se formen expectativas de largo plazo acerca de prevención de riesgos y responsabilidad de los fabricantes - de otro modo habrá cada vez menos productos para los consumidores y menos disponibilidad de aparatos médicos-. La manera de resolver esto es por medio de un proceso político creador de normas, e instituciones jurídicas orientadas a la resolución pacífica y ordenada

61 Véase Ted Schneyer, “The Promise and Problematics of Legal Ethics from the Lawyer's Point of View”, 16 Yale J. L. E Human., 45 (2003) (constatando la emergencia de esta perspectiva en la doctrina); Katherine R. Kruse, "The Jurisprudential Turn in Legal Ethics”, 53 Ariz. L. Rev., 493 (2011) (evaluando la segunda oleada desde adentro).

\footnotetext{
${ }^{62}$ Fried (nota 37).

${ }^{63}$ Véase John Rawls, Political Liberalism, pp. 54-58 (1993).
} 
de $\operatorname{conflictos}^{64}$. Esto es lo que a veces se denomina un "arreglo institucional". Toda sociedad requiere de un arreglo institucional para sobrevivir y prosperar. En particular, nuestro arreglo institucional contempla reglas respecto del ejercicio de la abogacía, que incluyen reglas éticas y reglas procedimentales. Aun cuando puedan no gustarnos los resultados que el arreglo produce para un caso particular, la sola existencia de una sociedad exige que obedezcamos el arreglo de todas formas.

Si los abogados se rehúsan a representar clientes porque objetan moralmente los fines del cliente, están violando los términos del arreglo institucional. Por supuesto, un abogado tiene derecho a rechazar a un cliente por razones morales. Pero ese rechazo debiera ser excepcional. De otra manera los abogados estarían efectivamente imponiendo sus convicciones morales a sus clientes, y de esa forma deshonrando el hecho del pluralismo social -el mismo pluralismo que un sistema democrático es llamado a preservar-. La preservación del pluralismo cuenta como una razón poderosa para que el abogado evite hacer deliberaciones morales de los fines del cliente o los medios legítimos para perseguir esos fines. Usando el lenguaje de la teoría del derecho, esta razón cuenta como una "razón excluyente" -una razón de segundo orden para no ejercer juicios morales de primer orden- ${ }^{65}$.

En un sentido menos abstracto, los abogados efectivamente entienden que lo que ellos hacen es respetar el arreglo institucional. Los abogados, y también los académicos cercanos a la práctica del derecho, a veces expresan enfado frente a lo que ellos identifican como una desaprobación generalizada desde el mundo filosófico hacia la abogacía ${ }^{66}$. Una de las motivaciones de la segunda oleada era tomarse en serio la posibilidad de justificar plenamente las prácticas de los abogados, independientemente de que parezcan "despreciables”, y luego intentar elaborar una fundamentación filosófica para ello. Las que siguen son las tres principales tesis de la segunda oleada de contribuciones académicas de ética profesional:

(1) La ética profesional es parte integrante de la filosofía política, no de la filosofía moral.

(2) La función política de las instituciones jurídicas es resolver disputas en una sociedad pluralista.

(3) Esto último exige que los abogados se abstengan de formular juicios morales de sus clientes, y entiendan que su rol es actuar como mandatarios de los clientes, y seguir las obligaciones jurídicas positivizadas en códigos de ética.

${ }^{64}$ Véase, e.g., ScOtт J. Shapiro, Legality, p. 213 (2011) (respecto del objetivo moral del derecho de enfrentar esta cuestión en comunidades políticas).

65 Joseph Raz, The Authority of Law, pp. 22-23 (1979).

${ }^{66}$ Véase, e.g., Monroe H. Freedman, "A Critique of Philosophizing About Lawyers' Ethics”, 25 Geo. J. Legal Ethics 91 (2012); M.B.E. SмIтH, "Should Lawyers Listen to Philosophers about Legal Ethics?”, 9 Law E Phil. 67 (1990); Ted Schneyer, "Moral Philosophy’s Standard Misconception of Legal Ethics”, 1984 Wis. L. Rev. 1529; Geoffrey C. Hazard, Jr., "My Station as a Lawyer”, 6 Ga. St. L. Rev. 1 (1989); Geoffrey C. Hazard, Jr. \& Dana A. Remus, “Advocacy Revalued”, 159 U. Pa. L. Rev. 751 (2011). Una crítica importante en Mark J. Osiel, "Lawyers as Monopolists, Aristocrats, and Entrepreneurs”, 103 Harv. L. Rev. 2009 (1990). 
El desarrollo del argumento se puede encontrar en el libro del filósofo neozelandés Tim Dare, y también en una monografía de uno de los autores del presente artículo (Wendel $^{67}$. Versiones ligeramente diferentes se pueden encontrar en los trabajos de Kate Kruse, Daniel Markovits, Alice Woolley, y Norman Spaulding, todos autores de la segunda oleada ${ }^{68}$.

Estos autores difieren en sus propuestas, y no todos defienden la versión tradicional de abogacía. Wendel, en particular, sostiene que el valor fundamental que los abogados deben defender es la fidelidad al derecho, no fidelidad a los fines del cliente ${ }^{69}$. Esto es especialmente importante cuando nos alejamos de la función del abogado como litigante y nos acercamos a su función como consejero o asesor. En este rol, el deber del abogado es ofrecer al cliente una opinión honesta y objetiva del derecho, aun cuando no sea lo que el cliente quiera escuchar. Por cierto, sabemos que los clientes corporativos siempre buscan que los abogados les digan que está permitido hacer lo que sea que ellos quieran hacer; pero el abogado debe ser leal al derecho, incluso si eso implica concluir que un cliente no está autorizado a celebrar un negocio.

Daniel Markovits comparte las premisas políticas del argumento de Wendel, incluyendo la noción de que el derecho tiene "un tipo de autoridad distintivamente política" respecto de los ciudadanos, derivada de la capacidad del derecho de hacer posible la mantención de un marco estable para el ejercicio del autogobierno, a pesar de la incompatibilidad de los intereses múltiples, y la pluralidad de convicciones morales razonables ${ }^{70}$. Pero Markovits pone un énfasis adicional en la participación de los ciudadanos en los procesos de autogobierno democrático, en los sentimientos afectivos de solidaridad de los miembros de la comunidad política, en el dominio común del resultado de procesos políticos, y en el potencial transformador de la participación política ${ }^{71}$.

Markovits sostiene que la principal virtud de la profesión jurídica es la que él denomina "capabilidad negativa"72. Este concepto, que él toma prestado del poeta John Keats, se refiere a la apertura a otros, y a la capacidad de hacer a un lado las propias preconcepciones. Keats lo describe como la capacidad "de estar sumido en incertidumbres, misterios, dudas, sin intentar iracundamente buscar la razón o los hechos"73. En vez de ejercer un juicio personal, el abogado debe "borrarse a sí mismo, o al menos sus

67 W. Bradley Wendel, Lawyers and Fidelity to Law (2010); Tim Dare, The Counsel of Rogues? A Defence of the Standard Conception of the Lawyer's Role (2009).

${ }^{68}$ Véase Daniel Markovits, A Modern Legal Ethics (2008); Alice Woolley, "The Lawyer as Advisor and the Practice of the Rule of Law", 47 UBC L. Rev. 743 (2014); Norman W. Spaulding, "Professional Independence in the Office of the Attorney General”, 60 Stan. L. Rev. 1931 (2007); Katherine R. Kruse, "Fortress in the Sand: The Plural Values of Client-Centered Representation", 12 Clinical L. Rev. 369 (2003); Kruse, "Beyond Cardboard Clients" (nota 15).

69 Véase WENDEL (nota 50), p. 59 (distinguiendo entre "derechos jurídicos" e intereses de clientes, y argumentando que solo los primeros debieran ser objeto de preocupación ética del abogado).

${ }^{70}$ Markovits (nota 68), pp. 174-75.

${ }^{71}$ Ibid., pp. 176-77, 180-82, 188-89.

${ }^{72}$ Ibid., pp. 93-95.

${ }^{73}$ Ibid., p. 94. 
convicciones personales de las demandas y causas que alega"74. Para Keats, la capabilidad negativa es la virtud esencial del poeta, quien, en su visión estética, debe impedir que su propia personalidad eclipse el objeto del poema: paradójicamente, quizás, la destreza del poeta consiste en volverse invisible para permitir que el poema brille. Muchos abogados litigantes asentirían afirmativamente: ellos ponen todo su empeño en lograr que la teoría del caso del cliente sea tan poderosa que llegue a hablar por sí misma, sin necesidad del desempeño del abogado.

Podríamos objetar la idea de que el mundo necesita abogados "negativamente capaces”, si es que por capabilidad negativa entendemos mover las propias convicciones a un lado $^{75}$. La causa principal de varios escándalos de alto perfil de la profesión jurídica en Estados Unidos, incluyendo la participación de abogados en la crisis de ahorros y préstamos de los años 80, y el impresionante ascenso y caída de Enron a principios de los $2000^{76}$, se encuentra en aquellos abogados que "se mantienen satisfechos sabiendo la mitad de las cosas" 77 . Sea lo que sea que digan los filósofos, las aseguradoras de estudios jurídicos ciertamente no recomiendan a los abogados que ejerzan "capabilidad negativa".

\section{El abogado como consejero}

Quizás el problema es que incluso si la capabilidad negativa es una virtud profesional para el abogado litigante, que reconstruye y defiende el caso del cliente, para el abogado consejero es un vicio. La manera correcta de caracterizar el rol del abogado como consejero surgió a partir de prácticas horrendas en el contexto posterior a los ataques terroristas de septiembre de 2001. Los abogados que trabajaban para el gobierno estadounidense escribieron media docena de informes en derecho secretos, validando prácticas de tortura de la CIA y otras violaciones al derecho internacional. Estos informes escritos eran muy poco sólidos, y algunos derechamente absurdos ${ }^{78}$. Los abogados cometieron el error fatal

${ }^{74}$ Ibid., p. 93.

${ }^{75}$ Así lo ha sostenido uno de nosotros: David Luban, "Review of Markovits", 120 Ethics, 864, $865-66$ (2010)

76 Véase, e.g., William H. Simon, "The Kaye Scholer Affair: The Lawyer's Duty of Candor and the Bar's Temptations of Evasion and Apology”, 23 Law E Soc. Inquiry 243 (1998) (criticando a los abogados por su papel en la crisis de ahorros y préstamos de los 1980's); Susan P. Koniak, "Where Were the Lawyers? Behind the Curtain Wearing Their Magic Caps", en Accountability Issues: Lessons Learned from Enron's Fall - Senate Judiciary Committee Hearing (Feb. 6, 2002) (refiriéndose al papel de los abogados en el escándalo financiero del fraude contable de 2002).

77 Véase Markovits (nota 68), p. 94 (citando la idea de capabilidad negativa de Keats).

${ }^{78}$ Véase, e.g., Harold H. Bruff, Bad Advice: Bush's Lawyers in the War on Terror (2009); Jens D. Ohlin, "The Torture Lawyers", 51 Harv. Int'l L.J. (2010); David Cole, "The Torture Memos: The Case Against the Lawyers", N.Y. Rev. of Books (Oct. 8, 2009); Jeremy Waldron, "Torture and Positive Law: Jurisprudence for the White House", 105 Colum. L. Rev. 1681 (2005); DAvid LubAN, "The Torture Lawyers of Washington", en Legal Ethics and Human Dignity, pp. 162-205 (revisado y expandido en David LuBAN, Torture, Power, and Law, pp. 197-253 (2014)). Los informes mismos aparecen reimpresos en David Cole, The Torture Memos: Rationalizing the Unthinkable (2009). 
de pensar que su deber era darle al Presidente y a la CIA lo que ellos querían, no lo que el derecho efectivamente exigía. Y el resultado fue una catástrofe ética.

¿Qué fue exactamente lo que estuvo mal de lo que hicieron los abogados? Una respuesta es obvia: la tortura es un mal grave, y la acción de los abogados hizo que fuera más probable que los detenidos bajo custodia en Estados Unidos fueran sometidos a tortura $^{79}$. Pero eso sería cierto respecto de cualquiera en esa posición; la pregunta para la ética de la profesión jurídica es si hubo algún vicio específico al ejercicio profesional en la autorización de estos memorandos referidos a tortura del Departamento de Justicia ${ }^{80}$. Para ponerlo de otra manera, ¿es la función del abogado empujar los límites hasta donde sea posible (en la litigación, en la asesoría, o en gestiones transaccionales o de planificación) para permitir al cliente hacer lo que el cliente quiera, o debiera el abogado operar más bien como un freno, de espíritu público, a las ambiciones de los clientes?

Por cierto, el caso de los "abogados de la tortura" nos presenta un contexto bastante atípico de asesoría legal. Pero el escándalo de los memorandos de tortura motivó una reflexión importante respecto de la función del abogado consejero que concierne a la práctica privada también. Los abogados del mundo privado a menudo sienten la presión ética de tener que ofrecerles a sus clientes un consejo "honesto e independiente" que sus clientes no desean escuchar, porque les muestra que no es posible obtener todo lo que desean, aun cuando esa es la función del abogado en el derecho positivo ${ }^{81}$. Y puede ocurrir que los abogados confundan su rol como asesor con el rol de un defensor cuya función es torcer el derecho para reconstruirlo de un modo amigable a los intereses del cliente, al menos hasta donde lo permita la prohibición de frivolidad. Puede ser, por ejemplo, que se sientan presionados a redactar informes que aprueban las transacciones que sus clientes quieren celebrar aun cuando el abogado no esté convencido que el derecho respalda esa posición. Uno de los argumentos más notables de Wendel es que el deber de fidelidad al derecho del abogado prohíbe esas jugarretas ${ }^{82}$. El deber de fidelidad al derecho fluye directamente de la importancia que esta segunda oleada pone en el derecho como una institución política funcional a la resolución de desacuerdos en una sociedad pluralista. Al exhibir fidelidad al derecho, al abogado no le será tan fácil justificar su función -estará debilitando precisamente la institución a la que apela cuando explica las razones por las que pone sistemáticamente sus convicciones morales a un $\operatorname{lado}^{83}$.

79 Véase, e.g., David Luban, “A Communicative Conception of Torture”, en Torture, Power, and Law, 111 (2014); David Sussman, "What's Wrong With Torture?”, 33 Phil. E Pub. Aff., 1 (2005); Henry Shue, "Torture", 7 Phil. E Pub. Aff., 124 (1978).

${ }^{80}$ Para una respuesta afirmativa, véase W. Bradley Wendel, "Executive Branch Lawyers in a Time of Terror: The 2008 F.W. Wickwire Memorial Lecture”, 31 Dalhousie L.J. (2008).

${ }^{81}$ Model Rules of Professional Conduct: Rule 2.1.

82 Véase, e.g., Wendel (nota 50), pp. 186-87.

${ }^{83}$ Queremos hacer notar que la crítica a la importación de la ética adversarial al contexto no adversarial de la asesoría legal no es exclusiva de la segunda oleada. Véase ya Lon Fuller \& John Randall, "Professional Responsibility: Report of the Joint Conference of the ABA-AALS”, 44 A.B.A.J. 1159, 1160-61 (1958) (distinguiendo la representación judicial de la asesoría); Luban, Legal Ethics and Human Dignity, caps. 4-5 (analizando la ética del rol de asesor y criticando los memorandos sobre tortura). Doctrinariamente se encuentra 


\section{El profesionalismo y la ética profesional}

Los líderes de las organizaciones profesionales por lo general se inclinan por "revivir" las concepciones tradicionales del profesionalismo, las que supuestamente florecieron a fines del siglo XIX y principios del siglo $\mathrm{XX}^{84}$. Se cita a veces a Elihu Root, un abogado que hizo una carrera de representar a "barones ladrones" como Jay Gould, diciendo: "[a]lgo así como la mitad de la práctica de un abogado decente consiste en decirle a potenciales clientes que son unos tontos testarudos y que debieran ponerle fin a sus acciones" 85 . Hay al menos alguna evidencia anecdótica de que abogados de grandes estudios alguna vez gozaron de independencia suficiente como para resistir la presión de sus clientes para asistirlos en conductas contrarias al interés público ${ }^{86}$. William Simon ha sostenido que Louis D. Brandeis, en su ejercicio privado como abogado antes de su nombramiento en la Corte Suprema, ejemplificaba los rasgos de este ideal de ejercicio profesional en su tiempo. ${ }^{87}$ Estos rasgos incluían la tendencia a disuadir a poderosos clientes institucionales de ejecutar "proyectos injustos y antisociales" y tener en consideración los intereses de aquellos terceros con quienes los clientes tenían negocios. La crítica concreta al desempeño estrictamente profesional de los abogados de la administración involucrados en la tortura de detenidos sería entonces, adoptando esta lógica, que ellos no procuraron que su asesoría fuera consistente con el interés público. Esto complementaría (y no estaría en conflicto con) la crítica en clave de moral ordinaria, respecto de la reprochable vulneración de la dignidad humana.

implícita en la distinción de las Model Rules entre, por un lado, el deber del abogado de representar el caso del cliente constreñido solo por la prohibición de frivolidad (Rule 3.1), y por otro, el deber del asesor de entregar una asesoría cándida e independiente (Rule 2.1); en el anterior Model Code of Professional Responsibility la distinción era explícita: EC 7-3 - 7-5. La contribución pionera del rol del asesor es StePHen L. PEPPER, "Counseling at the Limits of the Law: An Exercise in the Jurisprudence and Ethics of Lawyering”, 104 Yale L.J. 1545 (1995).

${ }^{84}$ Véase, e.g., ABA Commission on Professionalism, "In the Spirit of Public Service:" A Blueprint for the Rekindling of Lawyer Professionalism", reimpreso en 112 F.R.D. 243, 300 (1987).

${ }^{85}$ Gerald W. Gawalt, The New High Priests: Lawyers in Post-Civil War America, p. 4 (1984); Phillip C. Jessup, Elibu Root, Vol. 1, pp. 132-33 (1938). Root también dijo célebremente: "El cliente nunca quiere que se le diga que no puede hacer lo que quiere hacer; quiere que se le explique cómo hacerlo, y el rol del abogado es ofrecer esa explicación”. Robert T, Swaine, The Cravath Firm and its Predecessors, 1819-1947, p. 667 (1946). Considerando la clientela de Root, es probable que la segunda máxima sea más representativa de su concepción del profesionalismo del abogado. El historiador jurídico Lawrence Friedman afirmaba que los abogados siempre servían a sus propios intereses, luego a los clientes, y en último lugar a "su concepción de esa cosa difusa, nebulosa, llamada el interés público". Lawrence M. Friedman, A History of American Law, p. 639 (2da ed. 1985).

${ }^{86}$ Mary Ann Glendon, A Nation Under Lawyers, pp. 32-38 (1994); Samuel Haber, The Quest for Authority and Honor in the American Professions: 1750-1900, p. 224 (1991) (haciendo notar esa ansiedad de edad dorada sobre el "abogado como mercenario" que promueve los negocios de su cliente sin ninguna consideración por las exigencias de la justicia); Ibid., p. 238.

87 William H. Simon, The Practice of Justice, pp. 128-29 (1998). 
Por varias razones políticas, sociales y estructurales, rigurosamente documentadas por Rebecca Roiphe ${ }^{88}$, la concepción tradicional del profesionalismo ha colapsado, y en la actualidad los abogados están convencidos de que les está permitido, e incluso exigido, perseguir cualquier beneficio para sus clientes que pueda ser obtenido por medios que no violan explícitamente el derecho aplicable. Sin perjuicio de lo anterior, en un comentado libro de 1993 -que en varios sentidos representa un híbrido entre la primera y la segunda oleada- se propone una revitalización de la virtud clásica de la sabiduría práctica. El libro es The Lost Lawyer del exdecano de la Escuela de Derecho de Yale Anthony Kronman ${ }^{89}$. La "sabiduría práctica" consiste en la capacidad de apreciar empáticamente, pero a la vez con distancia, la posición del cliente. La distancia en particular exige un grado significativo de independencia del cliente ${ }^{90}$. El abogado debe apreciar el punto de vista del cliente sin necesariamente respaldarlo, a la vez que debe adoptar el punto de vista de otros y tomar en cuenta sus intereses y convicciones. ${ }^{91} \mathrm{El}$ abogado es un representante leal de clientes, pero es también un profesional de espíritu público, que actúa para preservar la integridad del esquema de leyes e instituciones jurídicas que hace posible que los intereses de los clientes se desarrollen ${ }^{92}$.

El libro de Kronman fue criticado por su abierto elitismo. No todos los abogados son capaces de ejercer esa sabiduría práctica. Para ilustrar su ideal profesional, Kronman invocó algunos “abogados de Estado” que alternadamente se desempeñaron en la administración pública y ejercieron como abogados en los mejores estudios jurídicos ${ }^{93}$. Pero es obvio que la excelencia en el ejercicio del juicio en representación de clientes no es exclusiva de célebres funcionarios del Estado que luego llegan a ser socios de grandes estudios. Abogados comunes, en pequeños pueblos y en grandes ciudades, muy bien podrían adquirir la capacidad de argumentar correctamente sus casos, apreciar esos casos como instancias de colisiones de valores, apreciar la posición del cliente con simpatía y distancia, y en último término tomar decisiones inteligentes por sus clientes. Una comprensión de la abogacía ética que enfatiza el ejercicio de un juicio profesional y la ponderación de valores públicos y privados puede resultar atractiva en la medida en que permita incluir como ejemplos abogados menos prominentes y poderosos que Robert Jackson, Dean Acheson y Cyrus Vance ${ }^{94}$.

\footnotetext{
${ }^{88}$ Rebecca Roiphe, “The Decline of Professionalism”, 29 Geo. J. Legal Ethics, 649 (2016).

${ }^{89}$ Anthony T. Kronman, The Lost Lawyer: Failing Ideals of the Legal Profession (1993).

${ }^{90}$ Este es también un tópico del trabajo de Bob Gordon quien, a pesar de ejercer principalmente como historiador antes que como filósofo, ha tenido una influencia considerable en la filosofía de la ética profesional. Véase, e.g., Robert W. Gordon, "Why Lawyers Can't Just Be Hired Guns", en Ethics in Practice: Lawyers' Roles, Responsibilities, and Regulation 46 (Deborah L. Rhode, ed., 2000); RoBERT W. Gordon, “The Independence of Lawyers", 68 B.U. L. Rev., 1 (1988).

91 Kronman (nota 89), pp. 69-70.

92 Ibid., p. 364.

93 Ibid., pp. 11-12, 283.

${ }^{94} \mathrm{O}$ al menos así lo ha sostenido uno de nosotros. Véase W. Bradley Wendel, "Professionalism as Interpretation", 99 Nw. U. L. Rev., 1169 (2005). Véase también Donald C. Langevoort, "Someplace
} 


\section{Las respuestas de la segunda oleada al desafío moralista}

Una cuestión que urge determinar es hasta qué punto las tesis de la segunda oleada exigen a los abogados abstenerse de deliberación moral, con el fin de preservar los arreglos institucionales de una sociedad pluralista. En este punto hay desacuerdo entre los autores del presente artículo, y creemos que este desacuerdo es sintomático de la diferencia entre la primera y la segunda oleada de la teoría de ética profesional -esto es, y como hemos explicado ya, la diferencia entre entender la ética profesional como una materia de filosofía moral o de filosofía política- ${ }^{95}$. La primera oleada, recuérdese, se pregunta si puede un abogado, como cuestión moral, actuar como una buena persona, aun cuando defienda fines moralmente cuestionables por medios moralmente cuestionables. Luban duda que la respuesta pueda ser sí, y propone por eso una alternativa -que denomina "activismo moral"-, en virtud de ello, el abogado deja siempre su interruptor moral en "encendido" y se involucra activamente con los clientes en la determinación de los fines y los medios $^{96}$. La otra perspectiva pone el foco en la importancia que tienen los abogados en un sistema jurídico que entreteje a una sociedad pluralista, y sostiene que los abogados tienen el deber de suspender sus juicios morales respecto de los fines del cliente y los medios legítimos necesarios para alcanzarlos ${ }^{97}$.

El argumento de la posición moralista es bastante directo: nuestra agencia moral siempre nos acompaña; no podemos evitarla. Es parte de la condición humana, de modo tal que un abogado nunca puede ignorar el daño que su representación puede infligir en otros. La solidaridad humana no puede exigir nada menos que esto. ¿Puede haber una razón genuinamente excluyente para esquivar la deliberación moral?

Una respuesta posible es: no; no hay razones excluyentes propiamente tal, pero sí es posible elevar la vara para hacer más difícil esquivar las exigencias de un $\mathrm{rol}^{98}$. Para una concepción bastante influyente de la "ética del rol", los titulares de un rol social pueden salirse del rol si es que, en el caso particular, la mejor manera de cumplir los objetivos del rol es hacer algo que en principio no está permitido por las reglas constitutivas del

Between Philosophy and Economics: Legitimacy and Good Corporate Lawyering”, 75 Fordham L. Rev., 1615 (2006) (con un argumento similar).

${ }^{95}$ Hemos explorado estos desacuerdos en varias contribuciones. Véase, e.g., W. Bradley Wendel, "Legal Ethics as "Political Moralism” or the Morality of Politics", 93 Cornell L. Rev., 1413 (2008) (reseñando David Luban, Legal Ethics and Human Dignity); David Luban, "The Inevitability of Conscience: A Response to My Critics", 93 Cornell L. Rev., 1437 (2008); David Luban, "Misplaced Fidelity”, 90 Texas L. Rev., 673 (2012) (reseñando W. Bradley Wendel, Lawyers and Fidelity to Law); W. Bradley Wendel, "Legal Ethics is About the Law, Not Morality or Justice”, 90 Texas L. Rev., 727 (2012).

${ }^{96}$ LuBAn, Lawyers and Justice (nota 1), pp. 148-74.

97 De modo más preciso, el abogado debe conformar su comportamiento al derecho positivo referido a la abogacía, que exige de un abogado que es incapaz de tomar distancia de su desaprobación moral de los motivos del cliente, que renuncie a la representación en razón de un conflicto de intereses: Model Rules $1.7(\mathrm{a})(2), 1.16(\mathrm{a})(1), 1.16(\mathrm{~b})(4)$.

98 Esta es la aproximación de Wendel: Wendel, Lawyers and Fidelity to Law (nota 50), p. 107 (sosteniendo que la regulación profesional "configura obligaciones hipotéticas, no conclusivas"). 
rol $^{99}$. La idea, sin embargo, no resuelve la siguiente objeción, a saber, que aun cuando la resolución de controversias en una sociedad pluralista es un bien moral, no es una cuestión tan importante como para asegurar razones excluyentes. Para Joseph Raz, que puso la noción de razones excluyentes en el centro de la teoría del derecho, es una verdad conceptual del derecho que este pretende autoridad, y que el ejercicio de autoridad supone la producción de razones formales, esto es, independientes del contenido ${ }^{100}$. Esta tesis conceptual deja abierta una pregunta normativa, a saber, si es que es bueno organizar una sociedad respecto de una lógica que exige a sus funcionarios y ciudadanos "separar sus convicciones sobre lo que el derecho manda o permite de sus convicciones individuales sobre la justicia o la moral" ${ }^{101}$. Cómo uno responda esta última pregunta determinará la afinidad que uno pueda tener ya sea por la primera o la segunda oleada.

Una segunda posible respuesta (propiamente de segunda oleada) al desafío moralista sugeriría que los moralistas de la primera oleada simplemente carecen de una psicología moral que les permita respaldar las exigentes demandas que dirigen a los abogados. Es simplemente imposible llevar una vida profesional en un estado constante de excitación moral, de la misma forma en que es imposible para un médico ejercer en las unidades de emergencia en un constante estado de angustia por sus pacientes. Los rasgos de personalidad que invocan los moralistas no son ni funcionales, ni realistas, ni deseables. Convertirían al abogado en un desadaptado social en el contexto de un estudio jurídico, y bajo la lógica de trabajo en equipo. Y la evaluación moral constante de los fines del cliente y de los medios presupone el despliegue de capacidades cognitivas y virtudes morales, de un modo absolutamente irrealista ${ }^{102}$.

Otra posibilidad para lidiar con el tormento que el derecho le causa a otros, que nos genera algo de simpatía, sería enfatizar que la ética pública opera en un mundo caracterizado por la necesidad de acuerdo. Los dilemas de la vida política, de los que la práctica del derecho es una parte, a veces son incapaces de ser resueltos si no queda la sensación de que hay algo objetable, o incluso incorrecto, en la solución a la que se arriba, aun cuando la conclusión misma esté justificada ${ }^{103}$. Max Weber le explica a los políticos que "[n]inguna ética del mundo puede eludir el hecho de que para conseguir fines 'buenos' hay que contar en muchos casos con medios moralmente dudosos” y que

99 Véase Mortimer H. Kadish \& Sanford H. Kadish, Discretion to Disobey: A Study of Lawful Departures from Legal Rules (1973).

100 Joseph Raz, “Authority, Law, and Morality”, en Ethics in the Public Domain, 210 (1994).

101 Jeremy Waldron, "Normative (or Ethical) Positivism”, en Hart's Postcript: Essays on the Postscript to The Concept of Law 411, 413 (Jules Coleman, ed., 2001).

102 Alice Woolley \& W. Bradley Wendel, "Legal Ethics and Moral Character", 23 Geo. J. Legal Ethics, 1065 (2010). Cf. David Luban, "How Should a Lawyer Be? A Reply to Woolley and Wendel", 23 Geo. J. Legal Ethics, 1101 (2010).

103 Véase, e.g., Bernard Williams, "Professional Morality and Its Dispositions", en The Good Lawyer (nota 14); reimpreso en Bernard Williams, Making Sense of Humanity (1995); Michael Walzer, "Political Action: The Problem of Dirty Hands", 2 Phil. E Pub. Aff. 160 (1973). 
“[q]uien no ve esto es un niño, políticamente hablando" 104 . Pidiendo prestada la oración del poderoso libro de Stuart Hampshire, ser un abogado implica experiencia, no inocencia:

[A]quellos que asumen las responsabilidades del poder político [...] deben en todo momento estar preparados para que ocurran conflictos de deberes incontrolados en situaciones que parecen excluir la posibilidad de un desenlace digno, y donde todas las líneas de acción parecen deshonorables y reprochables. Este es el punto en que el contraste entre inocencia y experiencia se vuelve indispensable en la ética. La idea de la experiencia es la idea del conocimiento culpable, de una expectativa de inevitable imperfección y miseria, de decepciones necesarias y resultados ambivalentes, de mitad éxito y mitad fracaso ${ }^{105}$.

La ética de las "manos sucias" no implica habituarse al uso de medios moralmente dudosos, sino reaccionar con aprensión al uso de medios moralmente dudosos -y estar preparado para reconocer cuándo las manos sucias se han vuelto "demasiado sucias"-. Solo un abogado que vacile o titubee al evaluar incurrir en los costos morales personales de participar de conductas incorrectas para avanzar los fines legítimos del cliente (cuando es estrictamente necesario), albergará la esperanza de evitar conductas incorrectas cuando no sean estrictamente necesarias, y de evitar el riesgo de racionalizar la conducta autointeresada y presentarla como el inevitable costo moral de ejercer poder público ${ }^{106}$.

\section{Conclusión: ¿UNA Tercera oleada?}

Comenzaremos esta sección conclusiva con una anécdota. En su primer año como profesor universitario de derecho, Wendel conoció a Luban, habiendo sido un admirador de su trabajo por muchos años. Se mostró impactado cuando Luban dijo, con algo de pesar: "Me temo que en el campo de la ética profesional filosófica ya está todo escrito, y no hay nada más que decir"107. Wendel, quien por naturaleza siempre iba en contra de la corriente, estaba decidido a mostrarle a Luban que estaba equivocado, y así terminó convirtiéndose, siete años más tarde, en un contribuyente en la producción académica de la segunda oleada. En un panel de una conferencia reciente, Wendel relató a los presentes esta historia, y concluyó reconociendo: "No estoy realmente seguro de qué queda por decir sobre ética profesional”. Y un panelista respondió: "Bueno, eso es lo que uno dice cuando está tan inmerso trabajando en su propio pequeño paradigma

${ }^{104}$ Max Weber, "Politics as Vocation", en From Max Weber: Essays in Sociology, 77, 121, 123 (Hans H. Gerth \& C. Wright Mills, eds., 1946).

105 Stuart Hampshire, Innocence and Experience, p. 170 (1989).

106 Bernard Williams, "Politics and Moral Character", en Moral Luck, pp. 62-63 (1981).

${ }^{107}$ Luban ahora piensa que esta es una de las afirmaciones más necias que recuerda haber hecho. Al menos espera no haber dicho cosas más necias que esa. 
y perdiéndose, por tanto, todas las cosas nuevas ocurriendo a tu alrededor" ${ }^{108}$. Punto concedido. Los autores hemos ofrecido este breve recuento histórico asumiendo nuestra posición de interlocutores de la primera y segunda oleada de teoría de ética profesional. Por esta razón no reclamamos tener acceso privilegiado a lo que podría surgir como tercera oleada. Pero estamos dispuestos a especular un poco. En lo que sigue planteamos algunas preguntas que creemos pueden ser áreas fructíferas de desarrollo para futuras contribuciones académicas de ética profesional.

\section{1. Ética profesional conductual}

Uno de los desarrollos más prometedores en filosofía moral es la incorporación (cautelosa) de hallazgos en psicología empírica en estructuras decisionales éticas. De esto el trabajo de Jonathan Haidt es probablemente lo más representativo ${ }^{109}$. Por supuesto, uno no puede derivar directamente un "debe" de un "es", pero los eticistas han empezado a reconsiderar algunas cuestiones filosóficas tradicionales relativas a la motivación, responsabilidad, personalidad, virtud, culpa, remordimiento, libre albedrío, determinismo y suerte moral, por referencia a la evidencia psicológica ${ }^{110}$. Los abogados por lo general se desenvuelven en contextos organizacionales, como estudios jurídicos u oficinas de asesoría interna. Existe actualmente un nutrido cuerpo de literatura pertinente a la manera en que los sistemas, prácticas y culturas organizacionales pueden fomentar comportamiento antiético ${ }^{111}$. Un número reducido de académicos de ética profesional ha empezado a disponer de estos descubrimientos ${ }^{112}$, pero el interés cada

108 Agradecimientos a Eli Wald.

109 Jonathan Haidt, “The Emotional Dog and the Rational Tail”, 108 Psych. Rev., 814 (2001).

${ }^{110}$ Véase, e.g., JOHn M. Doris, Lack of Character: Personality and Moral Behavior (2002); OwEN FLANAGAN, Varieties of Moral Personality: Ethics and Psychological Realism (1991); Gilbert Harman, "Moral Philosophy Meets Social Psychology: Virtue Ethics and the Fundamental Attribution Error”, 99 Proc. Aristotelian Soc'y 315 (1999). Un resumen enciclopédico se puede encontrar en el compendio de cinco volúmenes editado por Walter Sinnott-Armstrong y Christian Miller: Moral Psychology, The Evolution of Morality: Adaptations and Innateness (Walter Sinnott-Armstrong \& Christian B. Miller, ed., 2007); Moral Psychology: The Cognitive Science of Morality: Intuition and Diversity (Walter Sinnott-Armstrong, ed., 2007); Moral Psychology: The Neuroscience of Morality: Emotion, Brain Disorders, and Development (Walter Sinnott-Armstrong, ed., 2008); Moral Psychology: Free Will and Moral Responsibility (Walter Sinnott-Armstrong, ed., 2014); Moral Psychology: Virtue and Character (Walter Sinnott-Armstrong \& Christian B. Miller, ed., 2017).

111 Véase, e.g., John M. DARley, "How Organizations Socialize Individuals into Evildoing", en Codes of Conduct: Behavioral Research into Business Ethics 13 (David M. Messick \& Ann E. Tenbrunsel eds., 1996); Robert Jackall, Moral Mazes: The World of Corporate Managers (1988); Irving L. Janis, Groupthink: Psychological Studies of Policy Decisions and Fiascoes (2da ed. 1982).

112 Véase, e.g., Milton C. Regan Jr., Eat What You Kill: The Fall of a Wall Street Lawyer (2004); Milton Regan, "Moral Intuitions and Organizational Culture", 51 St. Louis U. L. J. 941 (2007); ANDREW M. Perlman, “A Behavioral Theory of Legal Ethics”, 90 Ind. L.J. 1639 (2015); Jennifer K. Robbenolt \& Jean Sternlight, "Behavioral Legal Ethics”, 45 Ariz. St. L.J. 1107 (2013); Donald C. Langevoort, "Chasing the Greased Pig Down Wall Street: A Gatekeeper's Guide to the Psychology, Culture, and Ethics of Financial Risk Taking”, 96 Cornell L. Rev. 1209 (2011). 
vez más elevado en torno a la relación entre derecho y psicología sugiere que todavía hay mucho que decir respecto de ética profesional conductual.

Tenemos dudas respecto de si subirnos al carro de la ciencia conductual. No hay duda de que una ética realista necesita comprender las estructuras cognitivas y organizacionales que dan forma al juicio moral individual. Pero a veces los psicólogos se entregan a una suerte de determinismo, esto es, a la idea de que la decisión humana en cuestiones morales es una ilusión. A veces escriben asumiendo que una comprensión exhaustiva de la situación externa en la que se halla el agente y de sus sesgos cognitivos internos nos permitiría concluir que aquello que parece una decisión libre en realidad no es tal ${ }^{113}$. Pero el "determinismo" es solo una posible aproximación al problema del libre albedrío, un problema que ha sido identificado por un distinguido filósofo como el más difícil de enfrentar para la filosofía ${ }^{114}$. Estamos inclinados a pensar que el determinismo en sí mismo es inútil para el razonamiento práctico: si me complica encontrar el curso de acción correcto, concluir "no depende de mî" es evadir el problema, y obviamente no contribuye a formarse una convicción. Ofrece nada más que una falsa comodidad por la vía de una salida fácil. Sin embargo, el giro conductual en la ética plantea cuestiones importantes en relación con las maneras de reorganizar estructuras prácticas para minimizar las presiones cognitivas y emocionales que ciertas situaciones imponen a nuestras convicciones morales y juicios prácticos.

Lo mismo se puede decir de una de las áreas más vanguardistas de la ética conductual: la aplicación de la neurociencia al razonamiento moral. Hay quienes han sostenido que identificar las estructuras cerebrales que se activan en las distintas operaciones del razonamiento moral nos puede ayudar a decidir qué teoría moral es verdadera ${ }^{115}$. A nosotros no nos convence. Si, por ejemplo, se descubriera que distintos patrones de razonamiento moral encienden una u otra sección del cerebro en una resonancia magnética, eso sería un hallazgo científico interesante, pero no nos diría nada sobre la validez de los juicios morales. En conclusión, si bien nos entusiasman los avances de la ética conductual, también creemos que hay algunos caminos más prometedores que otros para avanzar en la disciplina.

\section{2. Ética de la virtud}

Toda hazaña humana supone un agente, una acción, y consecuencias. Por milenos la filosofía moral ha tendido ha poner énfasis en uno u otro elemento de esta tríada. El

113 Véase, e.g. Melvin J. Lerner, The Belief in a Just World: A Fundamental Delusion 120 (198) (declarando que "cualquier psicólogo razonable” cree que “todo comportamiento es 'causado' por una combinación de eventos antecedentes y la dotación genética del individuo").

114 Susan Wolf, Freedom Within Reason, p, vii (1990).

115 Véase, e.g., Joshua D. Greene, “The Secret Joke of Kant's Soul”, en Moral Psychology: The Neuroscience of Morality: Emotion, Brain Disorders, and Development 35 (Walter Sinnott-Armstrong, ed., 2008); Joshua Greene, "Beyond Point-and-Shoot Morality: Why Cognitive (Neuro)Science Matters for Ethics", 124 Ethics 695 (2014). 
consecuencialismo se concentra en determinar si las consecuencias de las acciones son buenas o no; las teorías deontológicas se enfocan en la naturaleza intrínseca del acto. La perspectiva (que se remonta a Aristóteles) que se concentra en el "carácter" del agente se denomina "ética de la virtud". En años recientes especialistas en ética profesional de Australasia han estado participando de intensos debates acerca del papel que debieran jugar el carácter y la virtud en la ética de los abogados ${ }^{116}$, pero, salvo algunas excepciones $^{117}$, la disciplina no ha atraído la atención de autores angloamericanos. Quizás esto se explica porque la ética de la virtud no se desempeña en la casuística, que se encuentra en el corazón de la deliberación y decisión moral. Que se nos diga que el curso de acción correcto en un dilema moral es hacer "lo que una buena persona haría" es poco iluminador, aun cuando sea verdadero. Pero de todas formas creemos que cualquier construcción de ética profesional que no deje espacio para el agente se pierde de algo crucial. Esperamos que la ética de la virtud nos pueda ofrecer alguna guía en nuestras deliberaciones prácticas.

\section{Teoría de la relación fiduciaria}

La relación abogado-cliente, se nos recuerda constantemente, se origina en el mandato, porque los abogados son mandatarios de sus clientes. Como mandatarios, están sujetos a obligaciones fiduciarias para con sus clientes. La relación fiduciaria no es solo una relación jurídica; también es una relación moral -en la expresión de Cardozo en Meinhardv. Salmon: "es un detalle nimio del honor más delicado"- ${ }^{118}$. Estas obligaciones son la fons et origo [fuente y origen] de la ética profesional. En años recientes, los académicos han empezado a reconocer que las obligaciones fiduciarias -cuyo origen se encuentra en el contrato, pero de cierta forma trascienden la lógica individualista del derecho contractual clásico- son complejas ${ }^{119}$. Algunas porciones de la regulación disciplinaria, como las prohibiciones de conflictos de intereses, obviamente tienen como objetivo preservar la relación fiduciaria. Otras, como la prohibición de argumentos legales frívolos -y si vamos al caso, el compromiso del profesional con la representación pro bono- parecen tener otra fuente y origen. Para nosotros el análisis de la lógica fiduciaria de la relación abogado-cliente es una tarea de la filosofía moral y política.

Los tres tópicos mencionados -ética conductual, ética de la virtud, y teoría de la relación fiduciaria- nos plantean preguntas que recién han comenzado a explorar los especialistas en ética profesional. Si es que su desarrollo dará origen a una "tercera oleada” de producción filosófica de ética profesional es una cuestión que aquí no podemos

116 Véase Justin Oakley \& Dean Cocking, Virtue Ethics and Professional Roles (2001); Tim Dare, "Virtue Ethics and Legal Ethics", 28 Victoria U.-Wellington L. Rev., 141 (1998).

117 Véase, e.g., Heidi Li Feldman, "Codes and Virtues: Can Lawyers Be Good Ethical Deliberators?",

69 S. Cal. L. Rev., 885 (1996).

118 Meinhard v. Salmon, 249 N.Y. 458, 464 (1928).

${ }^{119}$ Véase, e.g., Philosophical Foundations of Fiduciary Law (Andrew S. Gold \& Paul B. Miller eds., 2016); Ethan J. Leib \& Stephen R. Galoob, “Fiduciary Political Theory: A Critique”, 125 Yale LJ.,1820 (2015-16). 
asegurar -nuestra bola de cristal está nubosa-. Además, nunca dijimos que las cuestiones levantadas por la primera y segunda oleada de ética profesional están definitivamente cerradas. Nos tienta concluir este artículo citando un anuncio encontrado en el escritorio de un filósofo alemán, que reza: "Yo no puedo resolver tus problemas; mi trabajo es ayudarte a disfrutar de ellos". 